\title{
Pool Boiling of Water on Surfaces with Open Microchannels
}

\author{
Robert Kaniowski * (D) and Robert Pastuszko \\ Faculty of Mechatronics and Mechanical Engineering, Kielce University of Technology, al. Tysiąclecia P.P. 7., \\ 25-314 Kielce, Poland; tmprp@tu.kielce.pl \\ * Correspondence: kaniowski@tu.kielce.pl
}

check for

updates

Citation: Kaniowski, R.; Pastuszko, R. Pool Boiling of Water on Surfaces with Open Microchannels. Energies 2021, 14, 3062. https://doi.org/ 10.3390/en14113062

Academic Editor: Patrick Phelan

Received: 28 April 2021

Accepted: 21 May 2021

Published: 25 May 2021

Publisher's Note: MDPI stays neutral with regard to jurisdictional claims in published maps and institutional affiliations.

\begin{abstract}
Boiling, as the most efficient type of convective heat transfer, is an area of interest in many fields of industry and science. Many works have focused on improving the heat transfer efficiency of boiling by altering the physical and chemical properties of surfaces by using different technological processes in their fabrication. This paper presents experimental investigations into pool boiling on enhanced surfaces with open microchannels. The material of the fabricated surface was copper. Parallel microchannels made by machining were about $0.2,0.3$, and $0.4 \mathrm{~mm}$ wide, 0.2 to $0.5 \mathrm{~mm}$ deep, and spaced with a pitch equal to twice the width of the microchannel. The experiments were carried out in water at atmospheric pressure. The experimental results obtained showed an increase in the heat flux and the heat transfer coefficient for surfaces with microchannels. The maximum (critical) heat flux was $2188 \mathrm{~kW} / \mathrm{m}^{2}$, and the heat transfer coefficient was $392 \mathrm{~kW} / \mathrm{m}^{2} \mathrm{~K}$. An improvement in the maximum heat flux of more than $245 \%$ and $2.5-4.9$ times higher heat transfer coefficient was obtained for the heat flux range of $992-2188 \mathrm{~kW} / \mathrm{m}^{2}$ compared to the smooth surface. Bubble formation and growth cycle in the microchannel were presented. Two static computational models were proposed to determine the bubble departure diameter.
\end{abstract}

Keywords: pool boiling; microchannel; heat transfer coefficient; bubble departure diameter; narrow gap

\section{Introduction}

Devices used in the power industry are designed to work in a given temperature range. To maintain the correct operating temperature, it is important to use suitable heat exchangers, using special surfaces to increase the heat transfer coefficient and the heat flux dissipated.

The dissipation of large amounts of heat is required when working with many technically advanced devices, including electronics used in hybrid vehicles, heat exchangers for hydrogen storage, supercomputers, computer data centers, X-ray medical equipment, avionics in aircraft and spacecraft, advanced radar, and laser and microwave-directed energy weapons [1].

Equipment that generates significant heat flux, such as electronics, gas turbines, nuclear reactors, and internal combustion engines, requires thermostabilization. In the design of such heat exchangers, the aim is to miniaturize the systems receiving and dissipating the heat flux as much as possible. For this purpose, different types of active and passive enhancement techniques [2] are used, related to flow [3-6] and pool boiling [7-12]. Hożejowska et al. [3] analyzed two-dimensional temperature distributions in rectangular, vertical, and nonaxial heated flat minichannels, finding five different two-phase flow patterns. Piasecka and Strąk [4] focused on two types of minichannel surfaces used for flow boiling enhancement, with randomly placed minicavities and with soldered metallic powder. The highest heat transfer coefficient was obtained for the enhanced foil with minicavities. The same authors [5] also investigated subcooled flow boiling in unequally heated rectangular minichannels oriented with few inclination angles. Piasecka and coworkers [6] computed the flow boiling heat transfer coefficient for a $1.7 \mathrm{~mm}$ depth minichannel with 
an enhanced surface during FC-72, HFE-649, HFE-7000, and HFE-7100 flow. Gil et al. [7] examined the influence of glow plasma water treatment at low pressure on pool boiling heat transfer. They observed a strong reduction in the heat transfer coefficient. In another work, Gil and Fijałkowska [8] determined the pool boiling heat transfer coefficients of selected refrigerants (RE170, R600a, and R601) and compared them with R134a. The highest performance was obtained for RE170. Hożejowska et al. [9] tested pool boiling heat transfer on surfaces with an open microchannel using ethanol as a working fluid. The highest heat transfer coefficient was obtained for the deepest and narrowest microchannel. Investigations of pool boiling of water, ethanol, and Novec-649 on surfaces with microchannels of variable and constant depth were carried out by Bedla-Pawlusek et al. [10]. The largest HTC at the boiling of water, about $45 \mathrm{~kW} / \mathrm{m}^{2} \mathrm{~K}$, was obtained for microchannels with a constant depth of $0.2 \mathrm{~mm}$. The results of investigations of the impact of mesh aperture on pool boiling heat transfer were presented by Orman [11]. He concluded that surfaces with meshes of smaller aperture provided better results. Orman and coworkers [12] also analyzed the pool boiling of water and ethanol on surfaces with microchannels made by laser treatment. The authors suggested that the samples with deeper microchannels and narrower fins provided the best performance.

The most effective and the most versatile passive technique of increasing the critical heat flux (CHF) and the heat transfer coefficient (HTC) comprises modification of the surface, which consists of changing the roughness of the heating surface, covering it with a porous layer, texturing, and applying perforations, forming subsurface tunnels, small fins, or microchannels.

Among the existing boiling liquids, water as a working fluid in contact with a copper surface provides the highest HTCs and CHFs. This liquid is generally available and relatively cheap, but its use in electronic systems is possible only in deionized and demineralized forms, because impurities cause corrosion and calcification in cooling channels.

Table 1 shows a summary of example surfaces with microchannels (MCs) used for pool boiling heat transfer intensification with water as a working fluid. Additionally, for comparison purposes, an example of a surface with a wire mesh is shown (last item).

Table 1. Types of open microchannels.

\begin{tabular}{|c|c|c|}
\hline Reference & Configuration & The Highest HTC \\
\hline Cooke and Kandlikar [13] & $\begin{array}{l}\text { Silicon microchannels } 0.04-0.2 \mathrm{~mm} \\
\text { wide and } 0.18-0.275 \mathrm{~mm} \text { deep, } \\
\text { etched in silicon plates }\end{array}$ & $73 \mathrm{~kW} / \mathrm{m}^{2} \mathrm{~K}$ \\
\hline Cooke and Kandlikar [14] & $\begin{array}{l}\text { Copper microchannels } 0.2-0.4 \mathrm{~mm} \\
\text { wide and } 0.100-0.400 \mathrm{~mm} \text { deep }\end{array}$ & $\begin{array}{l}269 \mathrm{~kW} / \mathrm{m}^{2} \mathrm{~K} \text { (channel } \\
\text { width: } 0.375 \mathrm{~mm} \text {; depth: } \\
0.4 \mathrm{~mm})\end{array}$ \\
\hline Jaikumar and Kandlikar [15] & $\begin{array}{l}\text { Microchannels } 0.3-0.762 \mathrm{~mm} \text { wide; } \\
\text { three configurations of copper } \\
\text { powder sintering: all surface, only } \\
\text { microfin tops, only microchannels }\end{array}$ & $\begin{array}{l}2900 \mathrm{~kW} / \mathrm{m}^{2} \mathrm{~K} \text {, relative } \\
\text { to the structured } \\
10 \times 10 \mathrm{~mm}^{2} \text { surface }\end{array}$ \\
\hline Patil and Kandlikar [16] & $\begin{array}{l}\text { Microchannels } 0.3-0.762 \mathrm{~mm} \text { wide } \\
\text { and } 0.2-0.4 \mathrm{~mm} \text { deep; microfin tops } \\
\text { with porous coatings }\end{array}$ & $\begin{array}{l}995 \mathrm{~kW} / \mathrm{m}^{2} \mathrm{~K} \text { (channel } \\
\text { width: } 0.762 \mathrm{~mm})\end{array}$ \\
\hline Jaikumar and Kandlikar [17] & $\begin{array}{c}\text { Microchannels } 0.762 \mathrm{~mm} \text { wide and } \\
0.4 \mathrm{~mm} \text { deep; coating } \\
\text { configurations as in [15] }\end{array}$ & $565 \mathrm{~kW} / \mathrm{m}^{2} \mathrm{~K}$ \\
\hline Gheitaghy et al. [18] & $\begin{array}{l}\text { Inclined }\left(45^{\circ}\right) \text { microchannels } \\
0.5-0.7 \mathrm{~mm} \text { wide and } 0.5-1 \mathrm{~mm} \\
\text { deep }\end{array}$ & $\begin{array}{c}\text { About } 120 \mathrm{~kW} / \mathrm{m}^{2} \mathrm{~K} \text { for } \\
\text { the channel width of } \\
0.5 \mathrm{~mm} \text { and depth of } \\
1.4 \mathrm{~mm}\end{array}$ \\
\hline Kaniowski et al. [19] & $\begin{array}{l}\text { Microchannels } 0.3 \mathrm{~mm} \text { wide and } \\
0.2-0.4 \mathrm{~mm} \text { deep }\end{array}$ & About $64 \mathrm{~kW} / \mathrm{m}^{2} \mathrm{~K}$ \\
\hline
\end{tabular}


Table 1. Cont.

\begin{tabular}{|c|c|c|}
\hline Reference & Configuration & The Highest HTC \\
\hline Rahman and McCarthy [20] & $\begin{array}{c}\text { Microchannels } 0.42-0.43 \mathrm{~mm} \text { wide } \\
\text { and } 0.25-0.31 \mathrm{~mm} \text { deep with } \\
\text { nanostructured coatings (copper } \\
\text { oxide) }\end{array}$ & $461 \mathrm{~kW} / \mathrm{m}^{2} \mathrm{~K}$ \\
\hline Kwak et al. [21] & $\begin{array}{l}\text { Microchannels } 0.03 \mathrm{~mm} \text { wide and } \\
0.01-0.1 \mathrm{~mm} \text { deep with a } \mathrm{SiO}_{2} \text { layer }\end{array}$ & $\begin{array}{l}\text { About } 60 \mathrm{~kW} / \mathrm{m}^{2} \mathrm{~K} \text { for } \\
\text { the microchannel depth } \\
\text { of } 0.1 \mathrm{~mm}\end{array}$ \\
\hline Walunj and Sathyabhama [22] & $\begin{array}{l}\text { Microchannels } 0.25-0.8 \mathrm{~mm} \text { wide, } \\
0.5 \mathrm{~mm} \text { deep; three types of shapes: } \\
\text { rectangular, parabolic, and stepped }\end{array}$ & About $16 \mathrm{~kW} / \mathrm{m}^{2} \mathrm{~K}$ \\
\hline Gouda et al. [23] & $\begin{array}{l}\text { Microchannels } 0.4 \mathrm{~mm} \text { wide and } \\
0.45 \mathrm{~mm} \text { deep and microfin } 0.2 \mathrm{~mm} \\
\text { wide }\end{array}$ & About $128 \mathrm{~kW} / \mathrm{m}^{2} \mathrm{~K}$ \\
\hline Zhang et al. [24] & $\begin{array}{l}\text { Minichannels } 0.8 \mathrm{~mm} \text { wide and } \\
1.5 \mathrm{~mm} \text { deep covered with } \\
\text { microporous copper structure with } \\
\text { a thickness of } 2-4 \mathrm{~mm}\end{array}$ & About $127 \mathrm{~kW} / \mathrm{m}^{2} \mathrm{~K}$ \\
\hline Li et al. [25] & $\begin{array}{c}\text { Sintered copper wire mesh } \\
0.21-2.3 \mathrm{~mm} \text { thick (pore size: } \\
0.119-0.232 \mathrm{~mm})\end{array}$ & About $175 \mathrm{~kW} / \mathrm{m}^{2} \mathrm{~K}$ \\
\hline
\end{tabular}

The departure diameter of the bubble is one of the most important parameters used to describe and model the boiling process on both plain and extended surfaces. The maximum diameter of the vapor bubble results from the balance of forces acting on it at the end of the growth period or at the beginning of the detachment period. Various methods of balancing the forces acting on a detaching bubble can be found in the literature. In relation to pool boiling on surfaces such as micro- and minichannels and micro- and minifins, the number of publications is limited.

Ramaswamy et al. [26] analyzed an enhanced structure with an array of microchannels on opposite sides. They considered six forces (surface tension, lift, vapor inertia, liquid inertia, buoyancy, and unsteady growth), the balance of which made it possible to determine the diameter of the detaching bubble. The authors additionally assumed that there is no inertia force when the velocity of the bubble is constant. Zhao et al. [27] analyzed pool boiling on surfaces with microfins with a width and height in the range of $0.2-0.8 \mathrm{~mm}$. For this kind of surface, they suggested that the drag force, pressure force, and inertia force could be neglected. Then, the force balance equation was shortened to surface tension, buoyancy, and capillary force balance; however, the authors did not perform calculations for the presented assumptions. Zhou et al. [28] presented a modified bubble dynamics model to predict the bubble departure diameter on a microfin surface. The traditional force balance model, additionally with Marangoni force, has been expanded by including the surface tension force of minor bubbles acting on the major bubble. Walunj and Sathyabhama [22] used a force balance similar to that given by Ramaswamy et al. [26] to estimate the bubble departure diameter for rectangular, parabolic, and stepped microchannels. The calculation of the surface tension force for the growing bubble was divided into two growth phases: in the space of the microchannel and at the tips of the microfins. The mean error between the calculated and experimental bubble detachment diameters for all microchannel surfaces was found to be $5.6 \%$. For surfaces with open microchannels, Cooke and Kandlikar [14] presented a simple relationship to calculate the diameter of the departing bubble, including the width of the microchannel and the contact angle. They found that the diameters of the bubbles on chips with $0.2 \mathrm{~mm}$ and $0.375 \mathrm{~mm}$ wide microchannels were larger than the analytical calculation by about $13 \%$. 
This article recapitulates the results of the pool boiling heat transfer experiments and theoretical analysis conducted on surfaces with microchannels. The study aimed to find the most advantageous microchannel geometry for the highest heat transfer coefficients and critical heat flux. The authors also proposed two methods of bubble departure diameter determination.

\section{Materials and Methods}

Heat transfer and visualization measurements were performed on the measurement system shown in Figure 1, being a modified set-up as described in $[29,30]$.

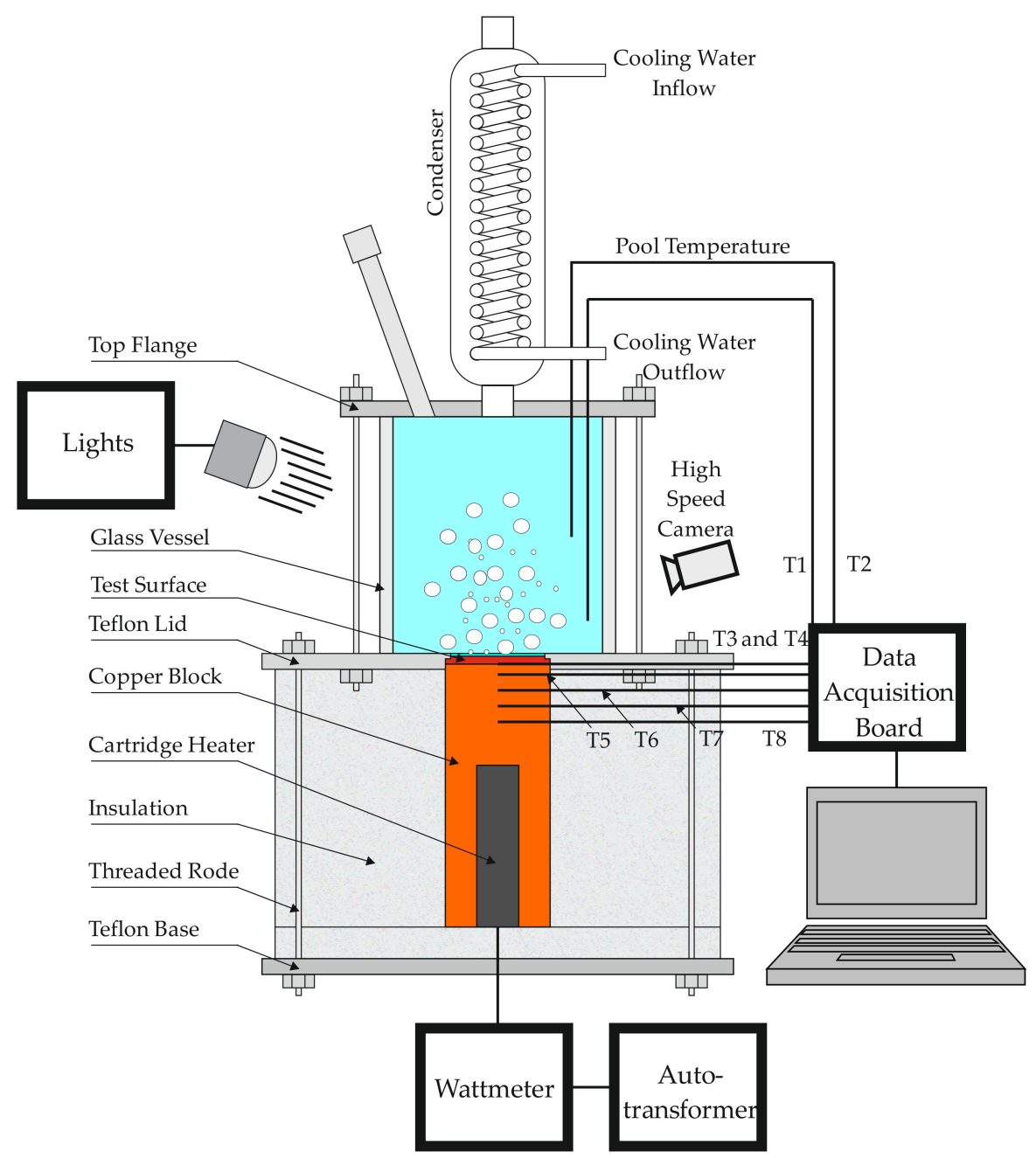

Figure 1. Pool boiling measurement stand.

The basic module enabled determining the temperature difference between the heating surface and the fluid and to evaluate the heat flux. Furthermore, the collected data could be used for creating the boiling curves $\alpha(\mathrm{q})$ and $\mathrm{q}(\Delta \mathrm{T})$. A $1500 \mathrm{~W}$ electric cartridge heater, $100 \mathrm{~mm}$ in length, $16 \mathrm{~mm}$ in diameter, was placed into the bar. Eight thermocouples (K-type, $\mathrm{NiCr}-\mathrm{NiAl}$ ) with a diameter of $0.5 \mathrm{~mm}$ were used for temperature measurements. Thermocouple calibration was performed using the Altek 422 calibrator with an accuracy and resolution of $0.1 \mathrm{~K}$. The absolute error of temperature measurement was taken as $0.2 \mathrm{~K}$ [31]. The FLUKE Hydra Series II measurement data acquisition station collected the readings from the thermocouples.

The linearity of the temperature values over a distance of $35 \mathrm{~mm}$ was examined and is presented in Figure 2. The coefficient of determination $R^{2}=0.99$ suggested one-dimensional 
heat conduction at the top of the heating cylinder. The arrangement of thermocouples in the heating cylinder is shown in Figure 3a.

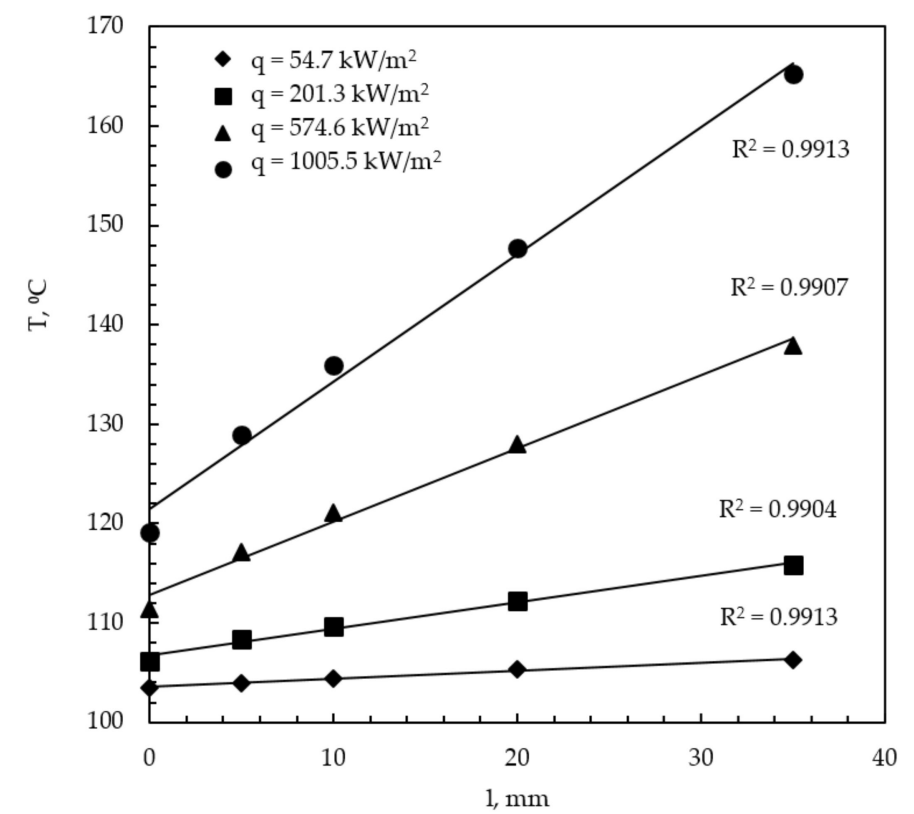

Figure 2. Temperature distribution at different heat fluxes: Specimen MC-0.3-0.4-0.6.

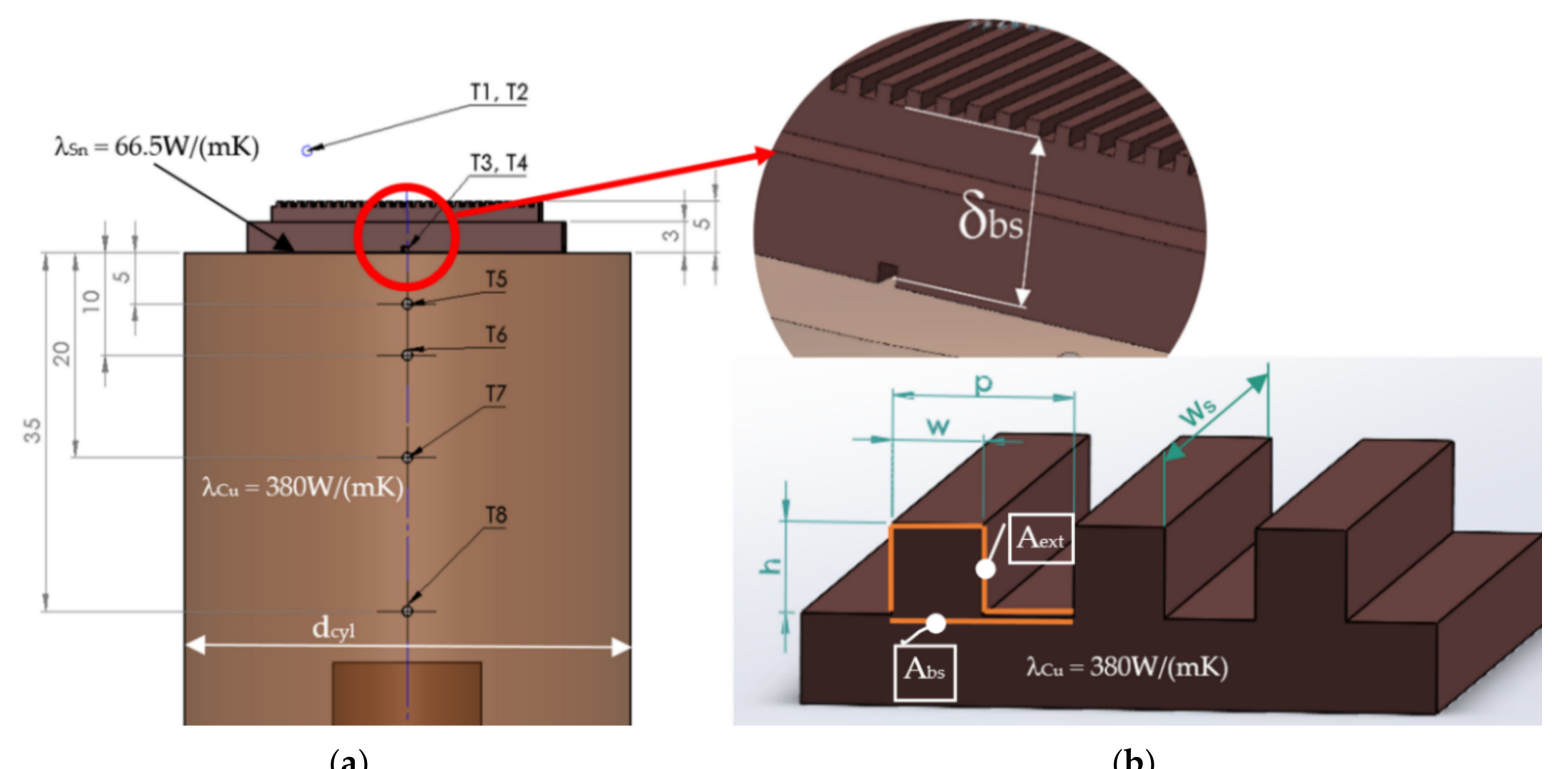

(a)

(b)

Figure 3. (a) Arrangement of thermocouples; (b) specimen with microchannel dimension.

A PHOT MV-D1024-160-CL (Photonfocus) digital monochromatic camera with a resolution of $1024 \times 758$ pixels was used for collecting images of bubbles at different heat fluxes. Photos were taken by the camera with a speed of $300 \mathrm{fps}$ and a resolution of $480 \times 360$ pixels, with an average error of $2 \mathrm{fps}$. For recording the whole surface of the specimen, the EX-FH20 (Casio) camera was used. During the visualization of the boiling process, front and side lighting with an LED lamp was used.

Prior to the actual measurements, the liquid was degassed for about $15 \mathrm{~min}$ in the main module by bringing it to a boil. Measurement data were collected when the temperature change did not exceed $0.1 \mathrm{~K}$ in $3 \mathrm{~min}$. Experiments were conducted at atmospheric pressure in distilled water with increasing heat flux to reach the boiling crisis (CHF). 
The surfaces with microchannels were made of copper and had parallel rectangular grooves made with an end mill (CNC machining process) (Figure 4a). The mean roughness was $0.123 \mu \mathrm{m}$. Tests were also carried out on a plain surface (Figure $4 \mathrm{~b}$ ) made of copper with a milling machine and polished with 600-grit sandpaper. The test section consisted of a $27 \times 27 \mathrm{~mm}^{2}$ boiling region on a $32 \times 32 \mathrm{~mm}^{2}$ square copper specimen. Table 2 compiles the surface codes and parameters of eleven MC surfaces according to the notations in Figure $3 b$.

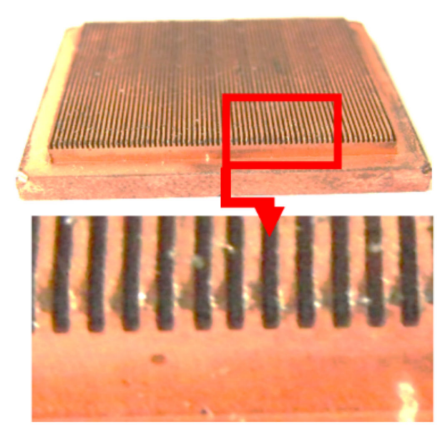

(a)

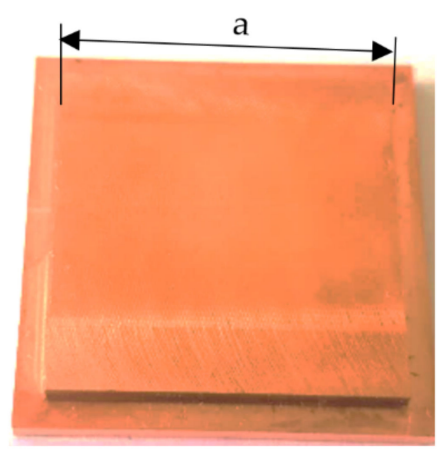

(b)

Figure 4. (a) View of the MC-0.2-0.5-0.4 surface and surface enlargement; (b) view of the plain, smooth specimen.

Table 2. Surface codes and specifications.

\begin{tabular}{ccccc}
\hline Specimen Code & w, $\mathbf{~ m m}$ & $\mathbf{h}, \mathbf{~} \mathbf{m}$ & $\mathbf{p}, \mathbf{m m}$ & $\boldsymbol{\varphi}$ \\
\hline MC-0.2-0.2-0.4 & 0.2 & 0.2 & 0.4 & 2.00 \\
MC-0.2-0.3-0.4 & 0.2 & 0.3 & 0.4 & 2.50 \\
MC-0.2-0.4-0.4 & 0.2 & 0.4 & 0.4 & 3.00 \\
MC-0.2-0.5-0.4 & 0.2 & 0.5 & 0.4 & 3.50 \\
MC-0.3-0.2-0.6 & 0.3 & 0.2 & 0.6 & 1.67 \\
MC-0.3-0.4-0.6 & 0.3 & 0.4 & 0.6 & 2.33 \\
MC-0.3-0.5-0.6 & 0.3 & 0.5 & 0.6 & 2.67 \\
MC-0.4-0.2-0.8 & 0.4 & 0.2 & 0.8 & 1.50 \\
MC-0.4-0.3-0.8 & 0.4 & 0.3 & 0.8 & 1.75 \\
MC-0.4-0.4-0.8 & 0.4 & 0.4 & 0.8 & 2.00 \\
MC-0.4-0.5-0.8 & 0.4 & 0.5 & 0.8 & 2.25 \\
\hline
\end{tabular}

The surface extension coefficient (enhancement factor) was defined as:

$$
\varphi=\frac{\mathrm{A}_{\mathrm{ext}}}{\mathrm{A}_{\mathrm{bs}}}
$$

where $A_{e x t}=(2 h+p) w_{s}, A_{b s}=p w_{s}$, and finally, $\varphi=(2 h+p) / p$ (Figure $\left.3 b\right)$. For instance, for Specimen MC-0.2-0.4-0.4, $\varphi=(2 \times 0.4+0.4) / 0.4=3$

According to Newton's law of cooling, HTC is equal:

$$
\alpha=\frac{\mathrm{q}}{\Delta \mathrm{T}}
$$

By Fourier's law:

$$
\mathrm{q}=\lambda_{\mathrm{Cu}} \frac{\mathrm{T}_{\mathrm{T} 8}-\mathrm{T}_{\mathrm{T} 5}}{\delta_{\mathrm{T} 8-\mathrm{T} 5}} \cdot \frac{\pi \mathrm{d}_{\mathrm{cyl}}^{2}}{4 \mathrm{a}^{2}}
$$


The wall temperature $\left(T_{\mathrm{w}}\right)$ was related to the microchannel bottom. Due to the shift of the thermocouples $\mathrm{T} 3$ and $\mathrm{T} 4, \mathrm{~T}_{\mathrm{w}}$ was extrapolated by the following equation:

$$
\mathrm{T}_{\mathrm{w}}=\frac{\mathrm{T}_{\mathrm{T} 3}+\mathrm{T}_{\mathrm{T} 4}}{2}-\mathrm{q}\left(\frac{\delta_{\mathrm{bs}}}{\lambda_{\mathrm{Cu}}}+\frac{\delta_{\mathrm{Sn}}}{\lambda_{\mathrm{Sn}}}\right)
$$

where $\delta_{\mathrm{bs}}$ is the distance between the microchannel bottom (reference surface) and thermocouples T3 and T4 (Figure 3a).

The wall superheat, defined as the difference between temperatures of the reference surface and the saturated liquid, is shown by the following equation:

$$
\Delta \mathrm{T}=\mathrm{T}_{\mathrm{w}}-\frac{\mathrm{T}_{\mathrm{T} 1}+\mathrm{T}_{\mathrm{T} 2}}{2}
$$

The diameter of the cylinder was $\mathrm{d}_{\mathrm{cyl}}=45 \mathrm{~mm}$, and the copper thermal conductivity was $\lambda_{\mathrm{Cu}}=380 \mathrm{~W} /(\mathrm{mK})$. A tin layer with a thickness of $0.1 \mathrm{~mm}\left(\delta_{\mathrm{Sn}}\right)$ and a thermal conductivity of $66.5 \mathrm{~W} / \mathrm{mK}\left(\lambda_{\mathrm{Sn}}\right)$ was used to attach the sample to the heating cylinder.

The measurement uncertainty of the heat flux was defined as the total differential error dependent on the errors in determining:

- The thermal conductivity coefficient $\Delta \lambda=1 \mathrm{~W} / \mathrm{mK}$;

- The temperature difference in the heating cylinder $\Delta\left(\Delta \mathrm{T}_{\mathrm{T} 5-\mathrm{T} 8}\right)=0.2 \mathrm{~K}$;

- The temperature difference $\Delta\left(\Delta \mathrm{T}_{\text {sat }}\right)=0.2 \mathrm{~K}$, where $\Delta \mathrm{T}_{\mathrm{sat}}=\left(\mathrm{T}_{\mathrm{T} 3}+\mathrm{T}_{\mathrm{T} 4}\right) / 2$ $\left(\mathrm{T}_{\mathrm{T} 1}+\mathrm{T}_{\mathrm{T} 2}\right) / 2$;

- The distance between the temperature sensors and the geometric quantities, i.e., diameter of the heating cylinder and side of the sample $\Delta \delta_{\mathrm{T} 5-\mathrm{T} 8}=\Delta \mathrm{d}_{\mathrm{cyl}}=\Delta \mathrm{a}=$ $0.00025 \mathrm{~m}$.

The dependence is shown by the equation:

$$
\Delta \mathrm{q}=\sqrt{\left(\frac{\partial \mathrm{q}}{\partial \lambda} \Delta \lambda\right)^{2}+\left(\frac{\partial \mathrm{q}}{\partial \Delta \mathrm{T}_{\mathrm{T} 5-\mathrm{T} 8}} \Delta\left(\Delta \mathrm{T}_{\mathrm{T} 5-\mathrm{T} 8}\right)\right)^{2}+\left(\frac{\partial \mathrm{q}}{\partial \delta_{\mathrm{T} 5-\mathrm{T} 8}} \Delta \delta_{\mathrm{T} 5-\mathrm{T} 8}\right)^{2}+\left(\frac{\partial \mathrm{q}}{\partial \mathrm{d}_{\mathrm{cyl}}} \Delta \mathrm{d}_{\mathrm{cyl}}\right)^{2}+\left(\frac{\partial \mathrm{q}}{\partial \mathrm{a}} \Delta \mathrm{a}\right)^{2}}
$$

On the other hand, the uncertainty of the heat transfer coefficient was determined as:

$$
\Delta \alpha=\sqrt{\left(\frac{\partial \alpha}{\partial \mathrm{q}} \Delta \mathrm{q}\right)^{2}+\left(\frac{\partial \alpha}{\partial \Delta \mathrm{T}} \Delta(\Delta \mathrm{T})\right)^{2}}
$$

where the uncertainty in the superheat measurement was defined as:

$$
\Delta(\Delta \mathrm{T})=\sqrt{\left(\frac{\partial \Delta(\Delta \mathrm{T})}{\partial \lambda} \Delta \lambda\right)^{2}+\left(\frac{\partial \Delta(\Delta \mathrm{T})}{\partial \Delta \mathrm{T}_{\mathrm{sat}}} \Delta\left(\Delta \mathrm{T}_{\mathrm{sat}}\right)\right)^{2}+\left(\frac{\partial \Delta(\Delta \mathrm{T})}{\partial \delta_{\mathrm{bs}}} \Delta \delta_{\mathrm{bs}}\right)^{2}+\left(\frac{\partial \Delta(\Delta \mathrm{T})}{\partial \mathrm{q}} \Delta \mathrm{q}\right)^{2}}
$$

For the considered heat fluxes, the relative error varied between $11.4 \%$ and $2.3 \%$ for heat fluxes $50-2188 \mathrm{~kW} / \mathrm{m}^{2}$ (Figure $5 \mathrm{a}$ ), while the relative error of the heat transfer coefficient was between $5.8 \%$ and $33.5 \%$ for the range of $35-392 \mathrm{~kW} / \mathrm{m}^{2} \mathrm{~K}$ (Figure $5 \mathrm{~b}$ ). Similar results of relative error calculations were obtained by Kandlikar and coworkers in the paper [15]. 


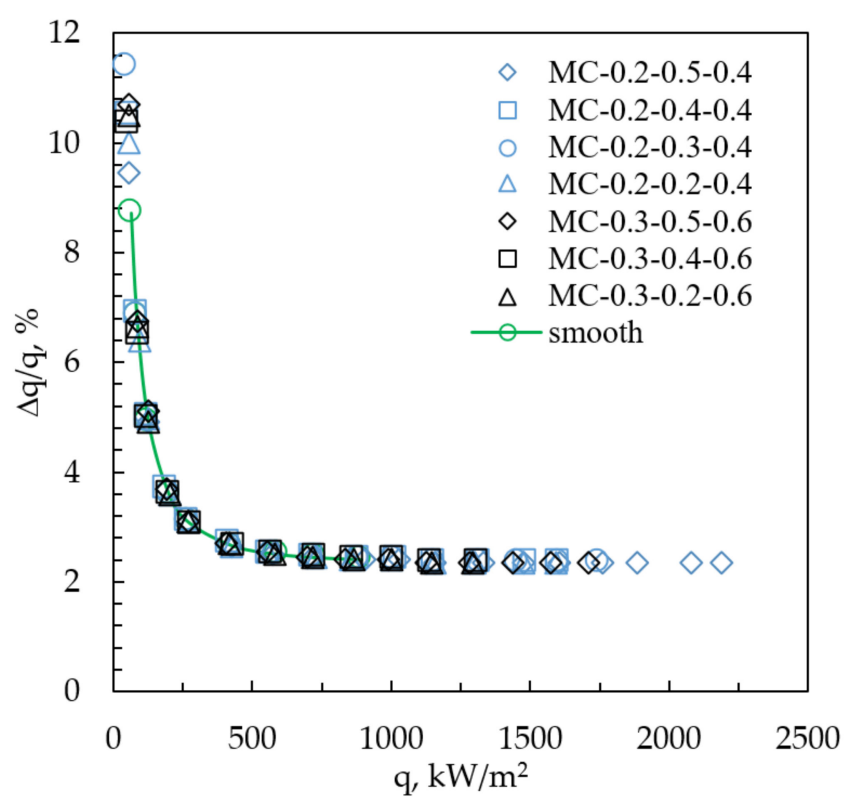

(a)

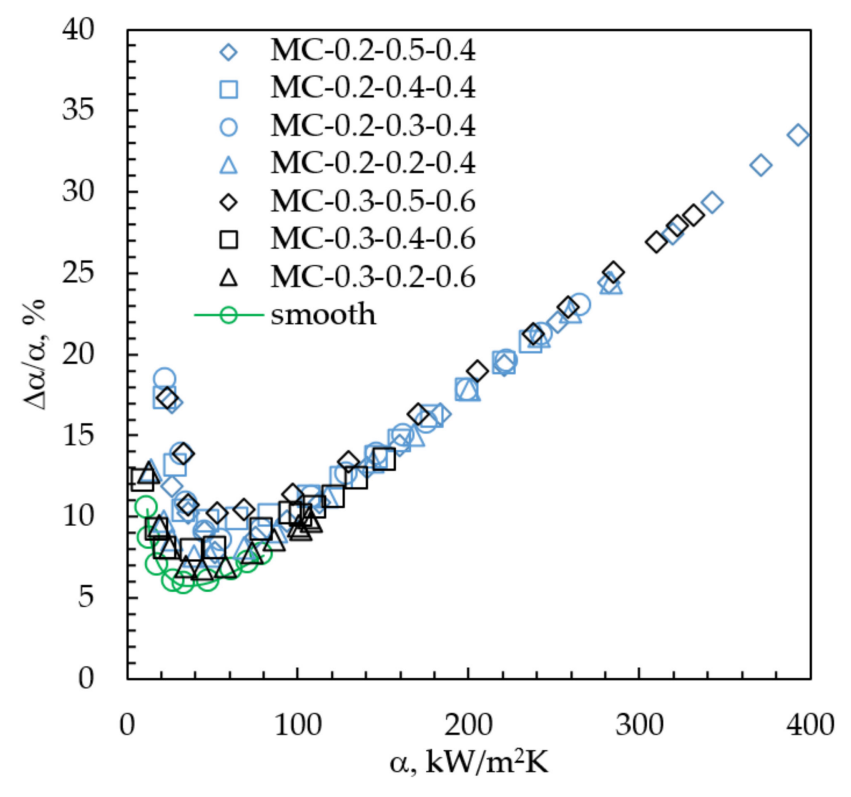

(b)

Figure 5. (a) Relative uncertainty at different heat fluxes; (b) relative uncertainties at different heat transfer coefficients.

\section{Results}

\subsection{Boiling Curves}

The measurement results for copper surfaces with microchannels are presented in the form of relationships $\alpha(q)$ (Figure 6) and $q(\Delta T)$ (Figure 7).

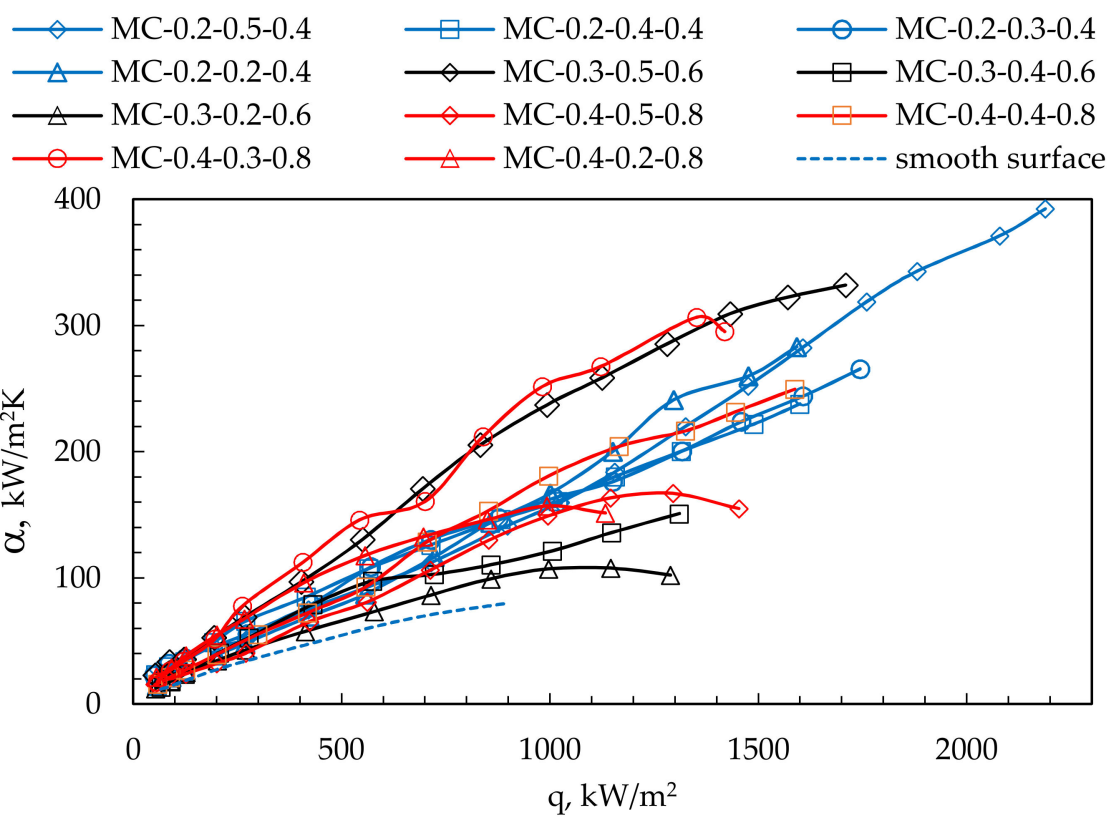

Figure 6. Boiling curves for water: heat transfer coefficient vs. heat flux. 


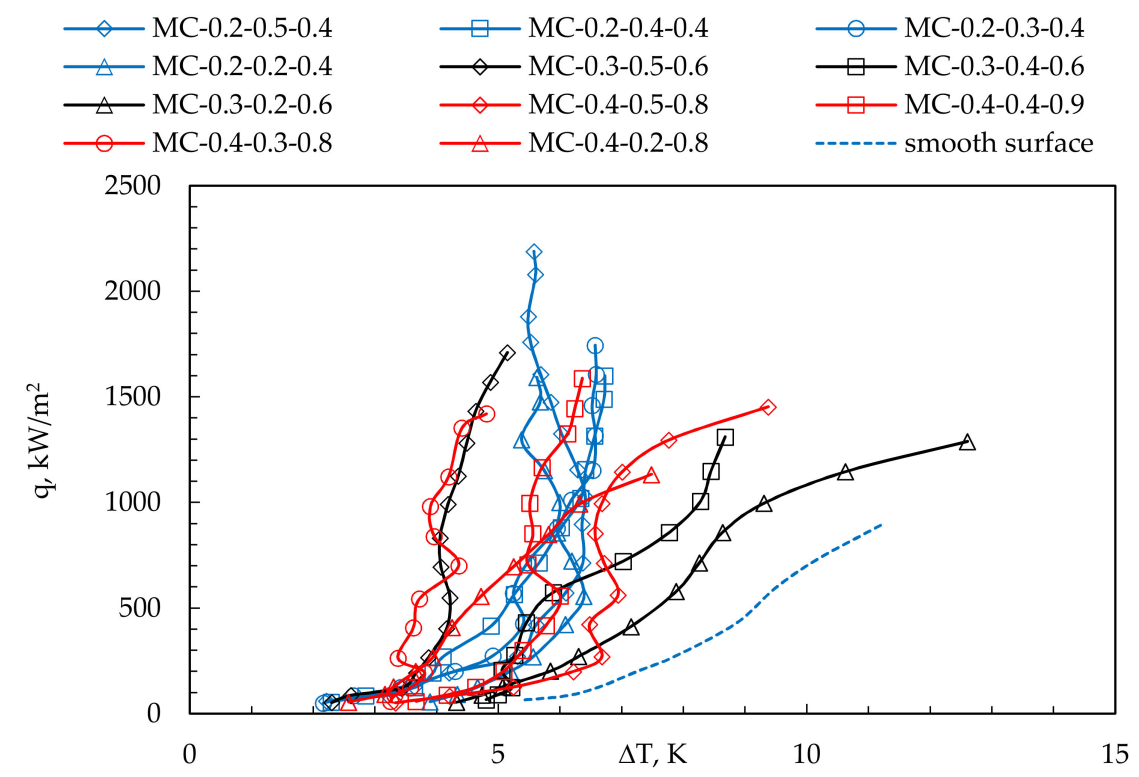

Figure 7. Boiling curves for water: heat flux vs. superheat.

The obtained boiling curves for the surface with microchannels were compared with the data for a plain smooth surface. The best performance was recorded for the surface MC$0.4-0.3-0.8$, whose HTC reached $306.5 \mathrm{~kW} / \mathrm{m}^{2} \mathrm{~K}$ in the range of up to about $1400 \mathrm{~kW} / \mathrm{m}^{2}$ at superheat $\Delta \mathrm{T} \approx 4.8 \mathrm{~K}$. However, on the MC-0.2-0.5-0.4 surface, the highest HTC was obtained $\left(392.4 \mathrm{~kW} / \mathrm{m}^{2} \mathrm{~K}\right)$ and $\mathrm{CHF}\left(2188 \mathrm{~kW} / \mathrm{m}^{2}\right)$ at superheat $\Delta \mathrm{T} \approx 5.6 \mathrm{~K}$. At such high heat fluxes, the relative error of HTC determination reached up to $33 \%$. Measurement results for the tested specimens may show discrepancies related to the change in parameters such as surface extension coefficient, roughness, and contact angle. Surface wettability can have a decisive effect on the value of HTC and CHF. In the paper [32], the authors described techniques improving this parameter, i.e., by using microporous surfaces, and decreasing the contact angle of copper surfaces by covering the surface with a thin layer of $\mathrm{SiO}_{2}$ and $\mathrm{TiO}_{2}$. Despite the lack of additional surface modifications, the analyzed surfaces allowed obtaining high HTCs within the range of $49.7-2188 \mathrm{~kW} / \mathrm{m}^{2}$. In relation to the plain smooth surface, for heat fluxes smaller than CHF, a 1.04-2.7-fold increase in HTC was obtained (Figure 8).

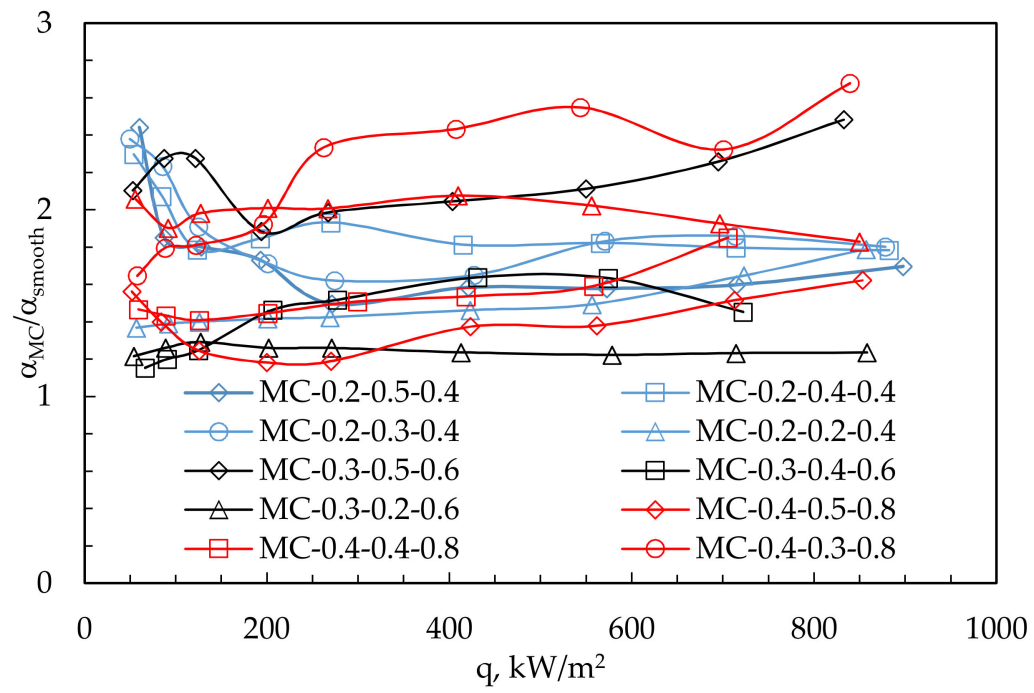

Figure 8. Heat transfer coefficient enhancement in nondimensional form for MC surfaces below the CHF for plain and smooth surfaces. 
For microchannels with a width of 0.2 and $0.3 \mathrm{~mm}$, the highest critical heat fluxes (CHFs) of about 2200 and $1700 \mathrm{~kW} / \mathrm{m}^{2}$, respectively, and the highest heat transfer coefficients (HTCs) of about 390 and $330 \mathrm{~kW} / \mathrm{m}^{2} \mathrm{~K}$, respectively, are obtained using the deepest microchannels $(\mathrm{h}=0.5 \mathrm{~mm})$. When the above-mentioned small microchannel widths are used, high capillary pressures, according to the relationship $\Delta \mathrm{p}_{\text {cap }}=2 \sigma \cos \Theta / \mathrm{w}$, ensure an adequate amount of liquid and compensate for the pressure drop during liquid inflow at the depth of $0.5 \mathrm{~mm}$. In addition, small pitches $(p=2 w)$ are used at small microchannel widths, hence the analyzed surfaces contain a significant number of microchannels, ensuring that a large number of nucleation sites are obtained. For surfaces with the smallest microchannel width $(0.2 \mathrm{~mm})$, an almost constant slight superheat of $5-6.5 \mathrm{~K}$ can be observed for heat fluxes above $500 \mathrm{~kW} / \mathrm{m}^{2}$ (Figure 7), which is important in obtaining large HTC values.

When using microchannels with a larger width $(\mathrm{w}=0.4 \mathrm{~mm})$, the medium depth of microchannels $(0.3-0.4 \mathrm{~mm})$ is the most beneficial. At this width, the diameters of detached bubbles are larger than for channels with widths of $0.2-0.3 \mathrm{~mm}$. The largest diameters according to the measurements were $4-4.3 \mathrm{~mm}$ for a $0.4 \mathrm{~mm}$ microchannel width, compared to diameters of $3.6-3.8 \mathrm{~mm}$ for $\mathrm{w}=0.2-0.3 \mathrm{~mm}$. Bubbles with larger diameters require more liquid to evaporate. The shallowest microchannels $(\mathrm{h}=0.2 \mathrm{~mm})$ do not ensure that an adequate mass flow rate of the inflowing liquid is maintained. However, by using the deepest microchannels $(\mathrm{h}=0.5 \mathrm{~mm}$ ), the lower capillary pressures obtained with a width of $0.4 \mathrm{~mm}$ do not compensate for the greatest pressure losses during the liquid inflow to this depth.

The surface extension coefficient value depends on the $h / p$ ratio, i.e., with the same pitch for large-depth microchannels, the highest $\varphi$ values are obtained. As for the tested MC surfaces, it was assumed that the pitch is twice the width, hence the dependence on the surface extension coefficient can be simplified to form $\varphi=\mathrm{h} / \mathrm{w}+1$. The MC-0.2-0.5-0.4 surface has the narrowest $(\mathrm{w}=0.2)$ and the deepest $(\mathrm{h}=0.5)$ microchannel, which allows for the highest coefficient value, $\varphi=3.5$, to be obtained. The deep microchannels are intensely supplied with liquid even at the biggest heat flux, which prevents them from drying out even at the highest superheating. Moreover, a higher value of $\varphi$ means a larger heat transfer surface and an increased number of microchannels. For a specimen width $\mathrm{w}_{\mathrm{s}}=27 \mathrm{~mm}$ and microchannel width $\mathrm{w}=0.2 \mathrm{~mm}, 134$ microchannels are obtained. The knowledge of the value of $\varphi$ allows for the estimation of the CHF increase for the compared surfaces. For example, the ratios of the surface extension coefficient for surface MC-0.2-0.5-0.4 to the surface extension coefficient for surfaces MC-0.2-0.3-0.4 and MC-0.3-0.5-0.6 are 1.4 and about 1.31, respectively. The CHF ratios for these surfaces are approx. 1.25 and approx. 1.28, respectively.

Surfaces with microchannels with a width of 0.2 (MC-0.2-0.5-0.4) and $0.3 \mathrm{~mm}(\mathrm{MC}-$ 0.3-0.5-0.6) have the highest surface extension coefficients (Table $2, \varphi=3.5$ and $\varphi=2.67$, respectively), which, with the efficiency of microfins $\eta$ ranging from 0.85 to 0.99 [9], guarantees high effectiveness $\varepsilon=\varphi \eta$. Similar conclusions regarding the influence of the surface extension coefficient on HTC were presented by Cooke and Kandlikar [13].

The data presented in this study for specimens MC-0.2-0.5-0.4 and MC-0.4-0.5-0.8 were compared to several other microstructured surfaces reported in Table 1 , as shown in Figure 9. The surface with microchannels with a width of $0.2 \mathrm{~mm}$ shows a CHF close to the values presented in the publications $[13,15,23,24]$, i.e., $1900-2700 \mathrm{~kW} / \mathrm{m}^{2}$, while allowing the highest HTC values. For an exemplary surface with $0.4 \mathrm{~mm}$ wide microchannels (MC0.4-0.5-0.8), the maximum HTC is obtained, similar to those presented in $[15,25]$, while the CHF is about 1.8-2.9 times smaller. 


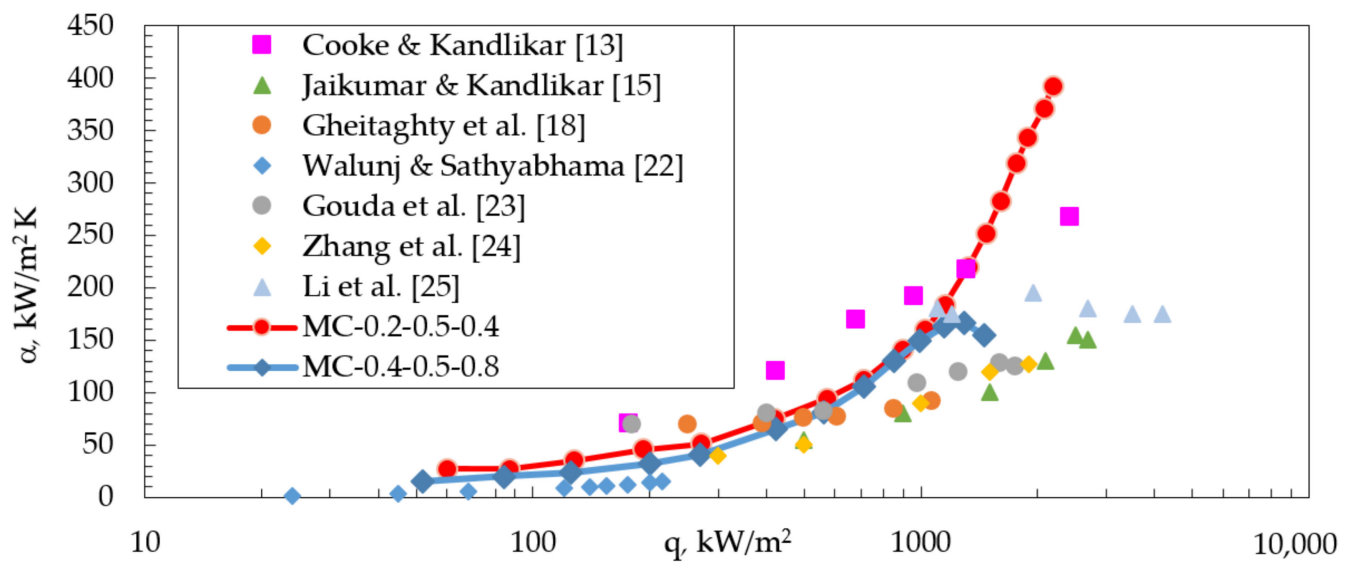

Figure 9. Pool boiling performance comparison with different structures reported in the literature with water as the working fluid [13,15,18,22-25].

\subsection{Visualization}

Relationships between the frequencies and diameters of departing bubbles are presented in Figure 10a. The experimental data were checked using the Zuber correlation [33]:

$$
\mathrm{fd}_{\mathrm{b}}=\mathrm{C}\left(\frac{\sigma \mathrm{g}\left(\rho_{1}-\rho_{\mathrm{v}}\right)}{\rho_{\mathrm{l}}^{2}}\right)^{0.25}
$$

where $\mathrm{C}=0.59$, and the Jakob correlation [34] is:

$$
\mathrm{fd}_{\mathrm{b}}=0.078
$$

With respect to the experimental data for boiling in microchannels, both correlations show underprediction. Correcting the $C$ factor in the Zuber correlation from 0.59 to 0.7 brings the experimental data within $\pm 20 \%$ (Figure 10a). For the analyzed microchannel surfaces, it is recommended that the modified Zuber correlation with the constant $C=0.7$ be used to predict the frequency for known values of the departing bubble diameter.

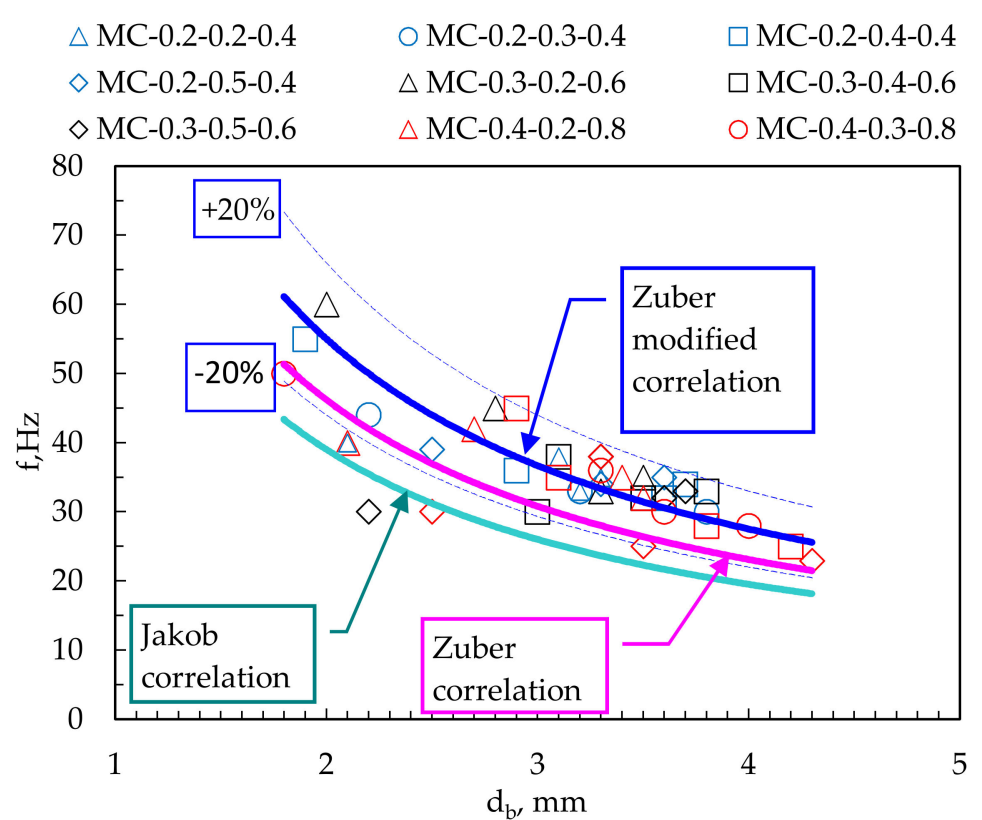

(a)

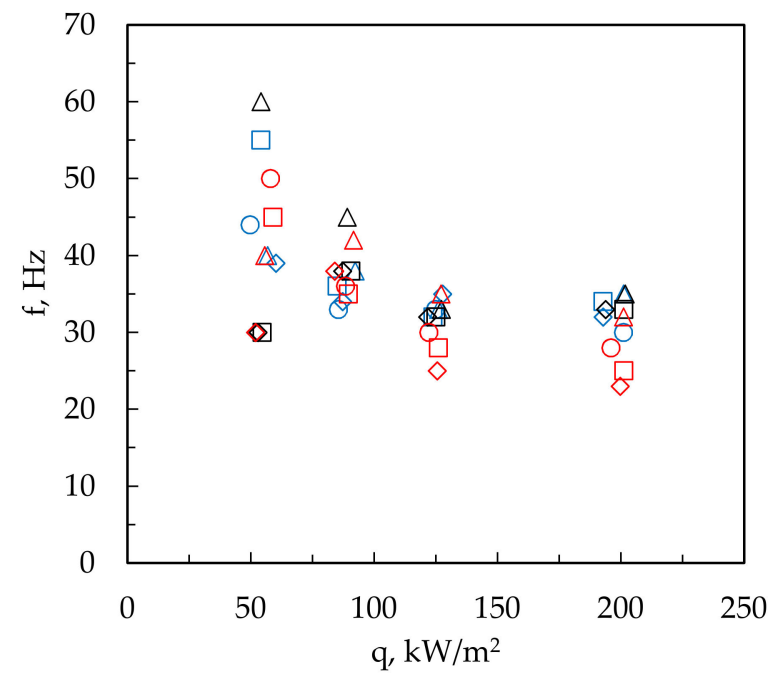

(b)

Figure 10. Averaged departing bubble frequency vs. departing bubble diameter (a) and heat flux (b). 
Figure 10b shows the dependence of bubble departure frequency on the heat flux. With small heat fluxes of $50-60 \mathrm{~kW} / \mathrm{m}^{2}$, vapor bubbles are formed with different diameters ranging from 2 to $3 \mathrm{~mm}$, and their frequency of detachment from the heating surface is variable $(30-60 \mathrm{~Hz})$. In the initial phase of nucleate boiling, the increase in heat flux causes a drop in the bubble departure frequency by about $70 \%$ and a simultaneous increase in the bubble diameter of $60 \%$ in the heat flux range of $q=50-90 \mathrm{~kW} / \mathrm{m}^{2}$ (Figure 10a,b). Nucleation sites operate at different frequencies, are scattered over the entire surface, and do not affect each other. At higher heat fluxes, for $\mathrm{q}>120 \mathrm{~kW} / \mathrm{m}^{2}$, the bubble frequencies stabilize (Figure 10b), while the number of nucleation sites increases. In the heat flux range of $120-200 \mathrm{~kW} / \mathrm{m}^{2}$, the frequency of the vapor bubbles remains approximately constant. Some nucleation sites are constantly active, continuously producing bubbles.

Figures 11 and 12 show the nucleate boiling for plain and extended surfaces with increasing heat flux. When boiling on a plain surface, there is intense coalescence above $100 \mathrm{~kW} / \mathrm{m}^{2}$. For surfaces with microchannels, even at higher heat flux, a significant number of isolated bubbles can be observed. At a heat flux of about $200 \mathrm{~kW} / \mathrm{m}^{2}$, the bubbles start to combine with each other before detachment (horizontal coalescence) and after detachment (vertical coalescence), as a result of which the vapor bubbles take funnel-like shapes at the bottom. For these vapor formations (bubble groups), the diameter and frequency of departing bubbles became impossible to measure.

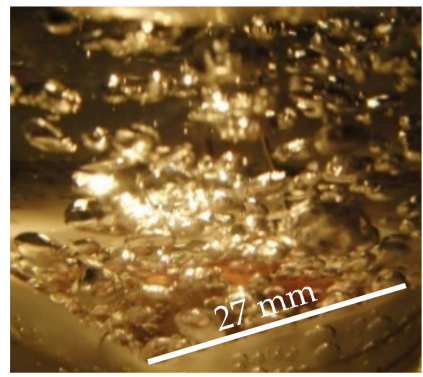

(a) $\mathrm{q}=65.8 \mathrm{~kW} / \mathrm{m}^{2}$

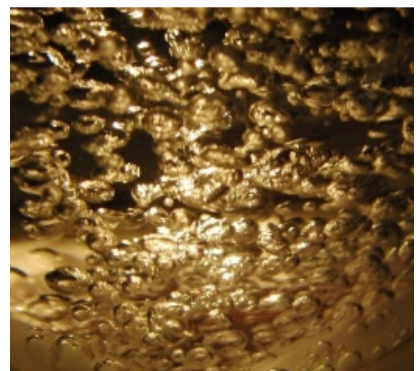

(b) $\mathrm{q}=85.8 \mathrm{~kW} / \mathrm{m}^{2}$

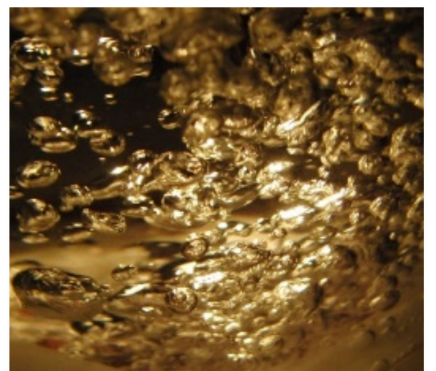

(c) $\mathrm{q}=127.4 \mathrm{~kW} / \mathrm{m}^{2}$

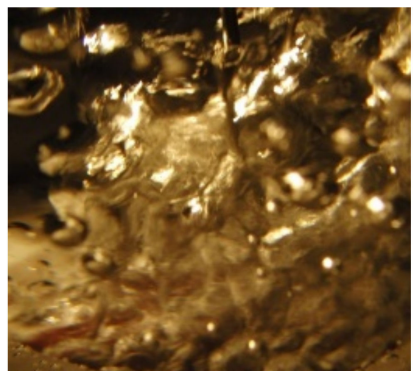

(d) $\mathrm{q}=200.4 \mathrm{~kW} / \mathrm{m}^{2}$

Figure 11. Visualization observation of pool boiling of water on the entire area of the plain smooth surface.

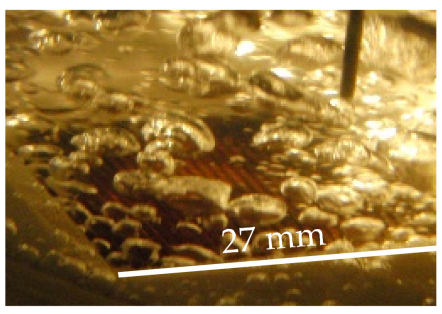

(a) $\mathrm{q}=51.9 \mathrm{~kW} / \mathrm{m}^{2}$

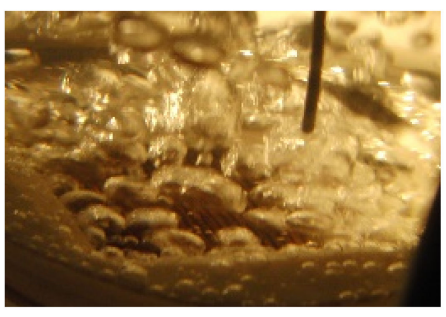

(b) $\mathrm{q}=84.0 \mathrm{~kW} / \mathrm{m}^{2}$

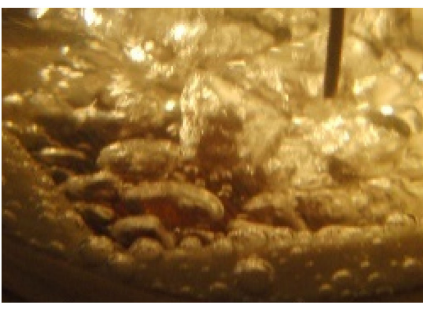

(c) $\mathrm{q}=125.6 \mathrm{~kW} / \mathrm{m}^{2}$

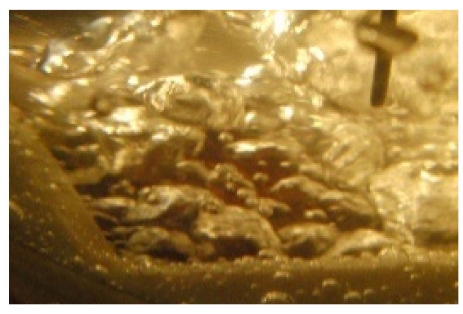

(d) $\mathrm{q}=199.7 \mathrm{~kW} / \mathrm{m}^{2}$

Figure 12. Visualization observation of pool boiling of water on the entire area of the surface with microchannels (MC-0.4$0.5-0.8)$.

\subsection{Bubble Formation and Growth}

Example images of isolated bubble growth on a surface with $0.4 \mathrm{~mm}$ wide microchannels are shown in Figure 13. The images show bubble growth above the microchannel space in contact with the edges of the microfins.

Another camera shot at an angle of $45^{\circ}$ (Figure 14) to the tested surface allowed for a more accurate analysis of the bubble formation and growth cycle in the microchannel space. 

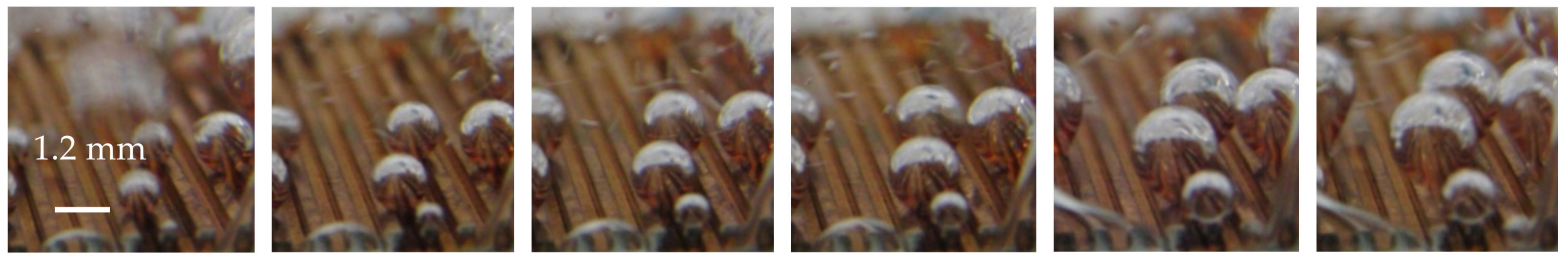

Figure 13. Successive images of growing isolated bubbles boiling on the MC-0.4-0.4-0.8 surface.

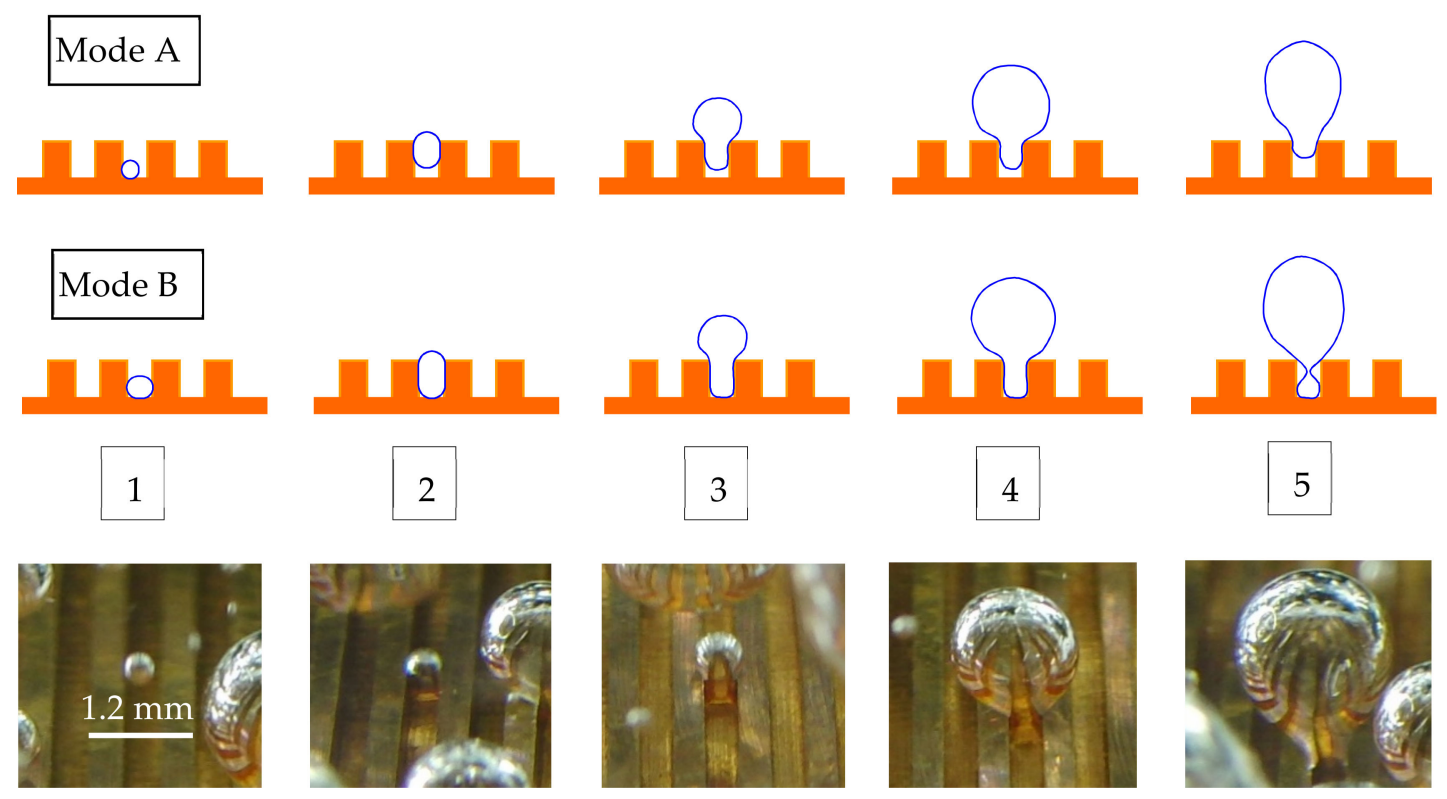

Figure 14. Bubble formation cycle in the microchannel of Specimen MC-0.4-0.4-0.8, $\mathrm{q}=90 \mathrm{~kW} / \mathrm{m}^{2}$ : (1) bubble at the channel bottom; (2) bubble growing in the microchannel space; (3) forming the bubble above the microfin tips; (4) the beginning of the detachment period; (5) bubble departure.

Bubble nucleation and growth in water at low and medium heat fluxes are shown in Figure 14. Analysis of the visualization images showed that the initial period of bubble growth is associated with its formation in a microchannel space limited by microfins. The observations made allowed us to distinguish between two modes (Mode A and Mode B) of nucleation, bubble growth, and departure. In the case of Mode A, which is characteristic of small heat flux, the microchannel spaces are almost filled with liquid and nucleation occurs in a corner near the bottom of the microchannel. The bubble expands to the width of the microchannel, then elongates and moves vertically, followed by the formation of the bubble above the microfin tips and an intense increase in the volume of the bubble, assuming a spherical shape above the microfin tip. At the same time, the volume of vapor filling the microchannel space decreases, resulting in an intense influx of liquid into the lower part of the microchannel, and the predominance of buoyancy force over the surface tension force results in the onset of the detachment period. A mechanism of bubble growth similar to the described one was presented by Walunj and Sathyabhama [22] in relation to a rectangular microchannel, distinguishing four phases of bubble growth: nucleation at the corner of the microchannel, growth in the channel, vertical bubble growth, and departure.

For higher heat flux, and therefore higher superheat, the lower part of the microchannel remains filled with vapor during the entire bubble formation cycle (Mode B). Subsequent stages related to the increase in the vapor volume in the microchannel space, without displacement of the whole bubble, and the formation of a spherical bubble above the microfin tip are similar to those in the discussed Mode A (Stages 2, 3, and 4; Figure 14). The primary difference is the separation of the expanded bubble from the vapor plug in the microchannel space (Stage 5; Figure 14). By leaving the vapor in the microchannel space, 
rapid formation and growth of a new bubble from the same nucleation site is possible at higher heat flux.

\subsection{Bubble Departure Diameter}

The existing dependencies for the bubble departure diameter calculation were developed for plain, smooth surfaces and therefore are of limited use on surfaces with microchannels. Due to the different mechanisms of the bubble cycle on surfaces with microchannels, the authors propose a new relationship for calculating the bubble departure diameter for these kinds of enhanced surfaces.

The diameter of the bubbles departing from the analyzed surface was calculated taking into account the buoyancy force and surface tension force balance. This simplified procedure ignores the inertia force, drag force, and pressure difference force during bubble growth. A similar simplification was adopted by Zhao et al. [27], analyzing the balance of forces acting on the bubble at boiling on plain surfaces. They concluded that the drag force and the inertia force played the most important role in the first period of bubble growth and were inconsiderable when coming to the critical departure point. Moreover, the pressure force is small enough to be neglected because, at the critical departure point, the pressure inside the bubble is almost equal to the liquid pressure. By adopting these simplifying assumptions, the following dependence can be obtained:

$$
\mathrm{F}_{\mathrm{bu}}=\mathrm{F}_{\mathrm{st}}
$$

Buoyancy force is calculated from:

$$
\mathrm{F}_{\mathrm{bu}}=\frac{\pi \mathrm{d}_{\mathrm{b}}^{3}}{6} \mathrm{~g}\left(\rho_{\mathrm{l}}-\rho_{\mathrm{v}}\right)
$$

and the surface tension force can be defined as:

$$
\mathrm{F}_{\mathrm{st}}=\sigma \mathrm{L}_{\mathrm{c}}
$$

For the correct determination of the surface tension force, it is necessary to determine the length of the contact line $\mathrm{L}_{\mathrm{c}}$, which is the line separating three phases: solid (surface material), liquid (saturated liquid), and gas (saturated vapor). According to Wang et al. [35] "during the bubble departure period, the vapor-liquid-solid triple contact line gradually recedes toward the center and the bubble shape changes from the spherical to ellipsoidal". At the same time, these authors assume that the changes in the bubble volume during the detachment period are insignificant, and the balance of forces refers to the beginning of the detachment period. For the analyzed surface with microchannels, this point corresponds to Stage 4 in Figure 14. The determination of the shape and length of the contact line relates to Mode B, i.e., higher heat flux.

Two methods were used to determine the length of the contact line, related to the possible position of the bubble on the microfins at the beginning of the detachment period.

\subsubsection{Method I}

The bubble base diameter $\left(\mathrm{d}_{\mathrm{bs}}\right)$ was assumed to span two adjacent microfins, with the bubble in contact with their faces, lateral surfaces, and the bottom of the microchannel (Figure 15a). In determining the contact line by this method, the presence of liquid in the corners of the microchannel near the bottom is ignored. The length of the contact line can be calculated from the relationship:

$$
\mathrm{L}_{\mathrm{c}}=\pi \mathrm{d}_{\mathrm{bs}}+4 \mathrm{~h}
$$

whereby given $\mathrm{d}_{\mathrm{bs}}=2 \mathrm{p}-\mathrm{w}$, we obtain:

$$
\mathrm{L}_{\mathrm{c}}=\pi(2 \mathrm{p}-\mathrm{w})+4 \mathrm{~h}
$$


Based on the force balance (Equations (11)-(13)) and Equation (14), the relationship for the diameter of the detaching bubble is obtained in the form:

$$
\mathrm{d}_{\mathrm{b}}=\left(\frac{6 \sigma[\pi(2 \mathrm{p}-\mathrm{w})+4 \mathrm{~h}]}{\pi \mathrm{g}\left(\rho_{1}-\rho_{\mathrm{v}}\right)}\right)^{1 / 3}
$$
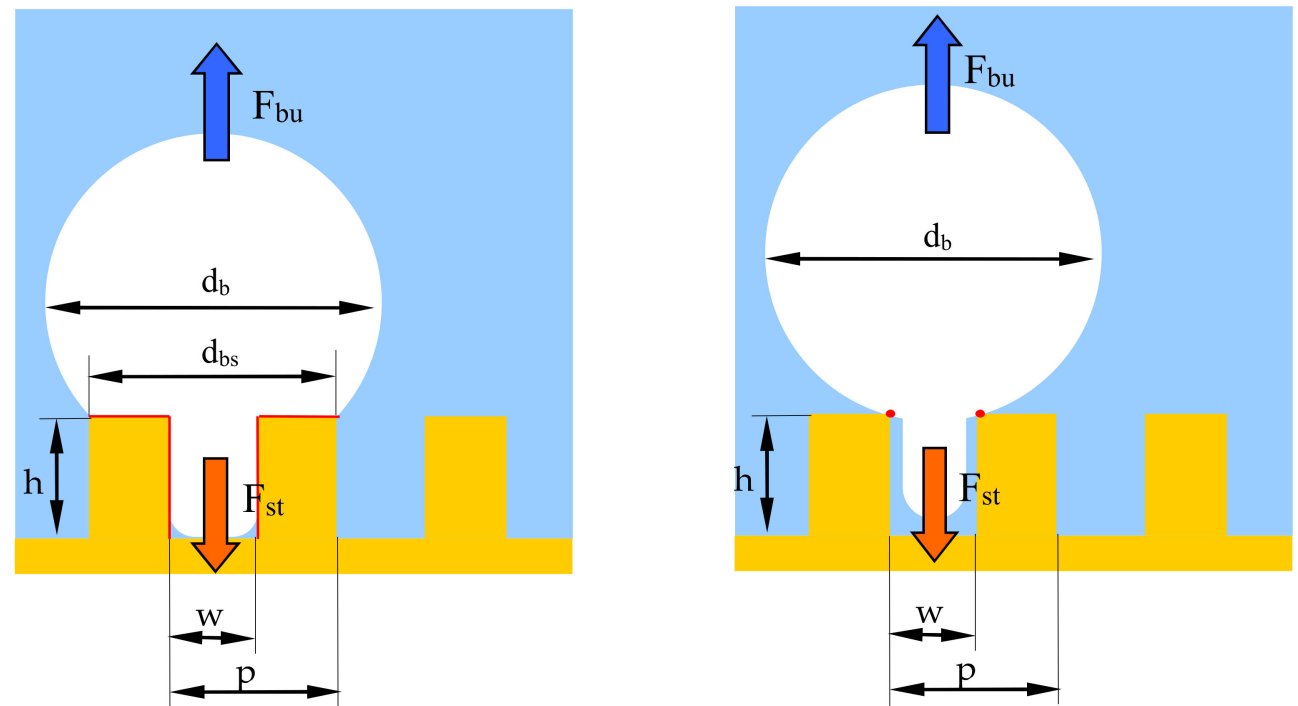

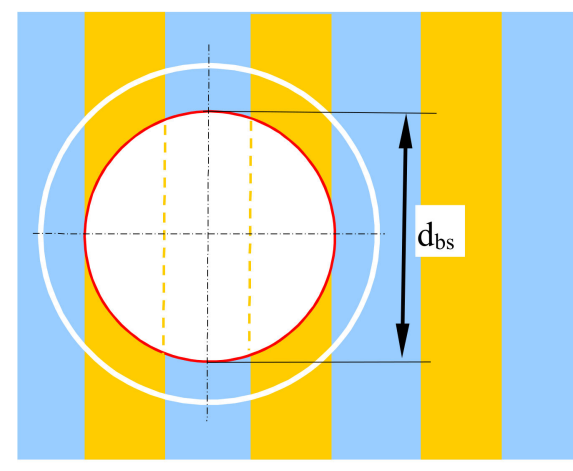

(a)

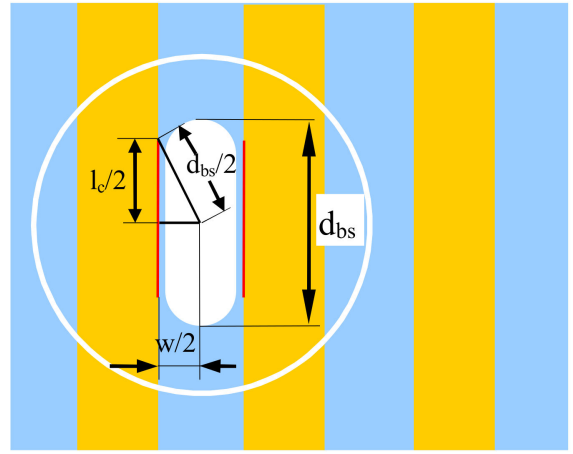

(b)

Figure 15. Two methods of determining the contact line: (a) Method I: contact with microfin tips, lateral surface, and the bottom of the microchannel, (b) Method II: contact with the microfin edge; the contact lines are marked in red.

\subsubsection{Method II}

In this case, the bubble was assumed to contact only the two edges of the microfin face on the microchannel side (Figure 15b). It was also assumed that there is a microlayer of liquid on the side surfaces of the microfin and the bottom of the microchannel, which prevents direct contact between the vapor and the walls in the microchannel space. The part of the bubble located in the microchannel space, between the microfins, is oval in shape, with the assumption that the larger dimension of the oval corresponds to the theoretical base diameter, i.e., the base of the spherical part of the bubble, $d_{b s}$. The geometrical relationships, derived from Figure 15b, allow the calculation of the contact line length $\mathrm{L}_{\mathrm{c}}=2 \mathrm{l}_{\mathrm{c}}$ :

$$
\mathrm{L}_{\mathrm{c}}=2 \sqrt{\mathrm{d}_{\mathrm{bs}}^{2}-\mathrm{w}^{2}}
$$


According to Wang et al. [35], as well as Beer [36], the ratio between the bubble base diameter and bubble departure diameter $\mathrm{d}_{\mathrm{bs}} / \mathrm{d}_{\mathrm{b}}$ during the bubble growth period is taken as $7 / 11$ for the plain surface. Such a ratio was also adopted for the analyzed surface with microchannels, assuming that the base of the bubble is limited only in one direction by the microfins forming the microchannel. Formula (17) then takes the form:

$$
\mathrm{L}_{\mathrm{c}}=2 \sqrt{\left(\frac{7}{11} \mathrm{~d}_{\mathrm{b}}\right)^{2}-\mathrm{w}^{2}}
$$

After substituting (18) into Equation (13), using Relationships (11) and (12), the following equation is obtained:

$$
\frac{\pi d_{b}^{3}}{6} g\left(\rho_{1}-\rho_{v}\right)=2 \sigma \sqrt{\left(\frac{7}{11} d_{b}\right)^{2}-w^{2}}
$$

The bubble diameters presented in Figure 16 were determined for the 4 th stage of the bubble formation cycle (Figure 14), i.e., for the beginning of the departing period. This period is characterized by slight changes in the diameter of the bubble, while the contact surface of the bubble with the side walls of the microchannels decreases rapidly. At the same time, the shape of the bubble changes from spherical to ellipsoidal. For the mentioned fourth stage, the balance of forces is performed by most authors who analyze the growth and detachment of the bubble on a plain surface. Figure 16 also shows two modes of bubble formation. Regarding Mode A, at small heat fluxes, where the bottom of the channel is filled with liquid, the departing bubbles have smaller diameters. With larger heat fluxes, the vapor fills almost the entire volume of the channel, which results in the detachment of larger diameter bubbles.

The numerical solution of the above equation gives the sought-after values of the bubble departure diameter. Figure $16 \mathrm{a}-\mathrm{c}$ shows a comparison of the measured bubble departure diameters with the values calculated according to Methods I and II. For microchannels with a width of $0.2 \mathrm{~mm}$, calculation Method I gives satisfactory results for heat fluxes above $80 \mathrm{~kW} / \mathrm{m}^{2}$, i.e., for diameters greater than $3 \mathrm{~mm}$, while calculations according to Method II give overprediction. For an average microchannel width $(0.3 \mathrm{~mm})$, the theoretical models are correct for heat fluxes of about $200 \mathrm{~kW} / \mathrm{m}^{2}$. Calculations according to Method II are similar to the calculations according to Method I for the deepest microchannels. For the widest microchannels $(0.4 \mathrm{~mm})$, both calculation methods give similar results and are correct for the largest heat fluxes. The results show that the bubble departure diameter increases with an increase in the microchannel width and depth. Using Method I, errors in determining the bubble departure diameter do not exceed $17 \%$ for heat fluxes greater than $100 \mathrm{~kW} / \mathrm{m}^{2}$, with errors decreasing to $8 \%$ for heat fluxes around $200 \mathrm{~kW} / \mathrm{m}^{2}$. For Method II, the obtained errors for the mentioned heat fluxes were $22 \%$ and $10 \%$, respectively. 

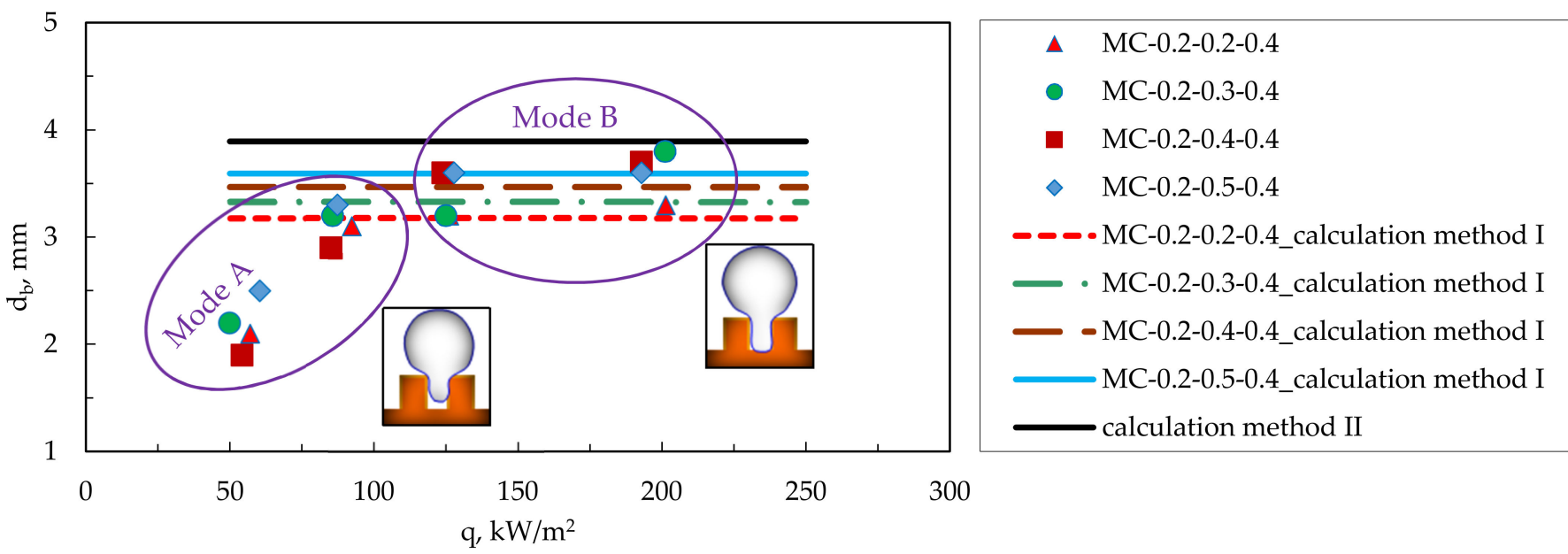

(a)

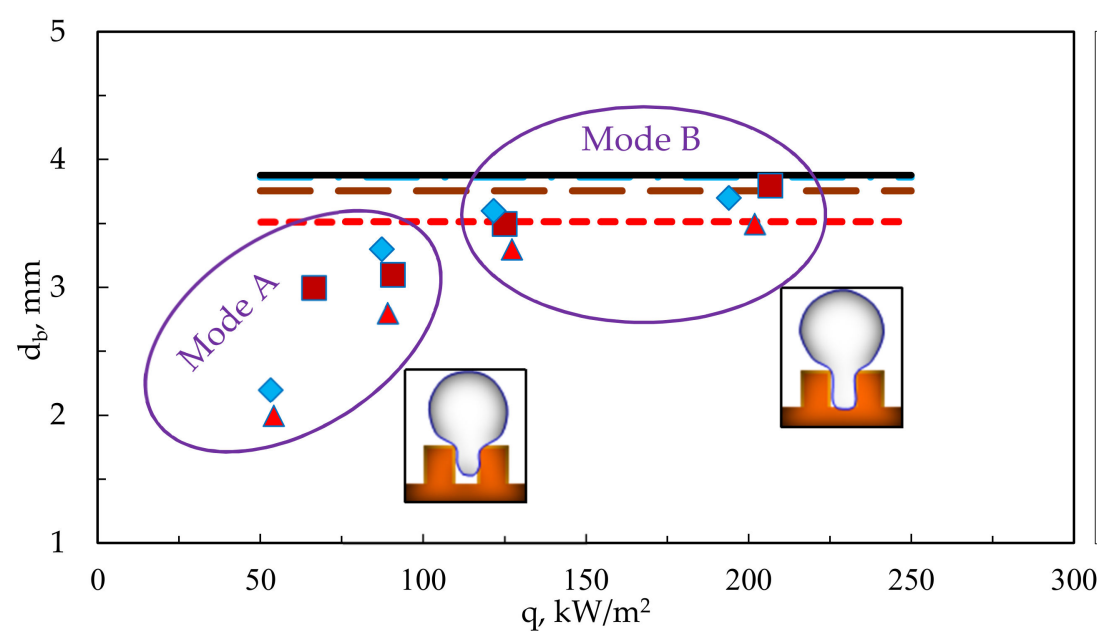

А MC-0.3-0.2-0.6

- MC-0.3-0.4-0.6

$\diamond \quad$ MC-0.3-0.5-0.6

- - MC-0.3-0.2-0.6_calculation method I

- MC-0.3-0.4-0.6_calculation method I

- MC-0.3-0.5-0.6_calculation method I

— calculation method II

(b)

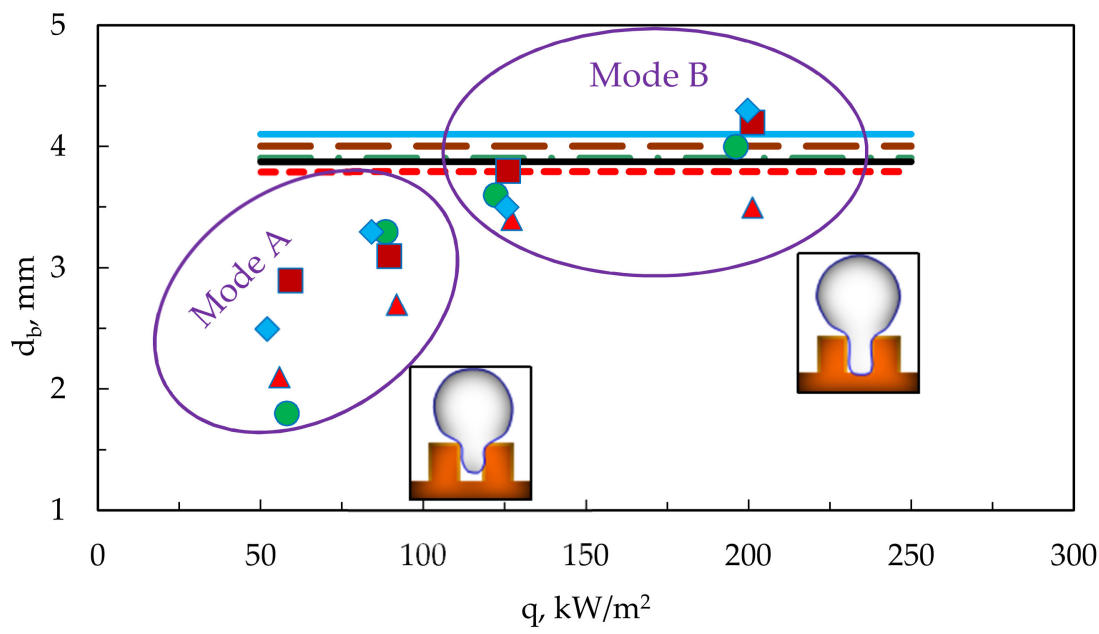

$\triangle \quad$ MC-0.4-0.2-0.8

- MC-0.4-0.3-0.8

- MC-0.4-0.4-0.8

$\diamond \quad$ MC-0.4-0.5-0.8

- - MC-0.4-0.2-0.8_calculation method I

- MC-0.4-0.3-0.8_calculation method I

- MC-0.4-0.4-0.8_calculation method I

MC-0.4-0.5-0.8_calculation method I

calculation method II

(c)

Figure 16. Comparison of measured and predicted bubble departure diameters for microchannels: (a) $0.2 \mathrm{~mm}$ wide; (b) 0.3 mm wide; (c) $0.4 \mathrm{~mm}$ wide. 


\section{Conclusions}

This article analyzes the pool boiling heat transfer of water on surfaces of rectangular microchannels with a depth of $0.2-0.5 \mathrm{~mm}$ and a width of $0.2-0.4 \mathrm{~mm}$. The effects of the geometrical dimensions of the surface and the surface extension coefficient on the critical heat flux and the heat transfer coefficient were presented. The HTCs of the selected surfaces were compared with the coefficients for seven different structures reported in the literature. Visualization of the isolated bubble formation cycle was carried out, and the diameters of departing bubbles were measured. Two methods of departing bubble diameter calculation were proposed in relation to the two kinds of determining the vapor-liquid-microchannel contact line.

The measurements and calculations led to the following conclusions:

- The surface with microchannels enabled obtaining more than a four-fold increase in the heat transfer coefficient in relation to the plain smooth surface with water as the boiling liquid.

- The highest HTCs and critical heat fluxes were obtained using microchannels with the smallest widths, i.e., $0.2-0.3 \mathrm{~mm}$. All surfaces analyzed allowed a significant increase in the maximum (critical) heat flux compared to the plain smooth surface: from 1.3 to 2.5 times.

- The surface extension factor (enhancement factor) has a significant impact on the value of the critical heat flux. Increasing this coefficient results in an almost linear increase in CHF.

- As the heat flux rises, the average diameter of the departing vapor bubbles increases while the departing frequency decreases. Above $100 \mathrm{~kW} / \mathrm{m}^{2}$, only slight increases in bubble diameter were recorded.

- The proposed modified Zuber correlation allowed to determine the dependence of the departing bubble frequency on the diameter of the microchannel surfaces with an error not exceeding $20 \%$.

- The article showed two possible modes of bubble formation and growth in the microchannel: with the microchannel partially filled with liquid or dried, i.e., almost filled with vapor.

- Two methods were presented to determine the bubble departure diameter, assuming that the bubble base covered two adjacent microfin tips or the bubble only contacted the two edges of the microfin face. Both calculation methods provided satisfactory accuracy for heat fluxes above $100 \mathrm{~kW} / \mathrm{m}^{2}$, i.e., assuming almost complete filling of the microchannel with vapor.

Author Contributions: Conceptualization, R.K. and R.P.; methodology, R.K. and R.P.; software, R.K. and R.P.; validation, R.K. and R.P.; formal analysis, R.K. and R.P.; investigation, R.K. and R.P.; resources, R.K. and R.P.; data curation, R.K. and R.P.; writing—original draft preparation, R.K. and R.P.; writing-review and editing, R.K. and R.P.; visualization, R.K. and R.P.; supervision, R.K. and R.P.; project administration, R.K. and R.P.; funding acquisition, R.K. and R.P. All authors have read and agreed to the published version of the manuscript.

Funding: This research received no external funding.

Institutional Review Board Statement: No applicable.

Informed Consent Statement: Not applicable.

Data Availability Statement: The data presented in this study are available on request from the corresponding author.

Conflicts of Interest: The authors declare no conflict of interest. 


\section{Nomenclature}

\begin{tabular}{|c|c|}
\hline A & Area, $\mathrm{m}^{2}$ \\
\hline a & Width of specimen, $\mathrm{m}$ \\
\hline $\mathrm{C}$ & Constant \\
\hline $\mathrm{CHF}$ & Critical heat flux, $\mathrm{W} \mathrm{m}{ }^{-2}$ \\
\hline d & Diameter, $\mathrm{m}$ \\
\hline $\mathrm{F}$ & Force, $\mathrm{N}$ \\
\hline $\mathrm{f}$ & Frequency, $\mathrm{Hz}$ \\
\hline g & Gravitational acceleration, $\mathrm{m} \mathrm{s}^{-2}$ \\
\hline HTC & Heat transfer coefficient, $\mathrm{W} \mathrm{m}^{-2} \mathrm{~K}^{-1}$ \\
\hline $\mathrm{h}$ & Microchannel depth, $\mathrm{m}$ \\
\hline $\mathrm{L}$ & Total length, $\mathrm{m}$ \\
\hline 1 & Length, $\mathrm{m}$ \\
\hline$q$ & Heat flux, $\mathrm{Wm}^{-2}$ \\
\hline $\mathrm{p}$ & Pitch, m \\
\hline $\mathrm{T}$ & Temperature, $\mathrm{K}$ \\
\hline $\mathrm{W}$ & Width, m \\
\hline \multicolumn{2}{|c|}{ Greek letters } \\
\hline$\alpha$ & Heat transfer coefficient, $\mathrm{W} \mathrm{m}{ }^{-2} \mathrm{~K}^{-1}$ \\
\hline$\Delta$ & Error, uncertainty \\
\hline$\Delta \mathrm{T}$ & Superheat referred to the microfin base, $\mathrm{K}$ \\
\hline$\Delta \mathrm{p}$ & Pressure difference, $\mathrm{Pa}$ \\
\hline$\delta$ & Thickness, $\mathrm{m}$ \\
\hline$\varepsilon$ & Fin effectiveness \\
\hline$\eta$ & Fin efficiency \\
\hline$\Theta$ & Contact angle, rad \\
\hline$\varphi$ & Surface extension coefficient \\
\hline$\lambda$ & Thermal conductivity, $\mathrm{W} \mathrm{m}{ }^{-1} \mathrm{~K}^{-1}$ \\
\hline$\rho$ & Density, $\mathrm{kg} / \mathrm{m}^{3}$ \\
\hline$\sigma$ & Surface tension, $\mathrm{N} / \mathrm{m}$ \\
\hline \multicolumn{2}{|l|}{ Subscripts } \\
\hline $\mathrm{b}$ & Departing bubble \\
\hline bs & Base \\
\hline bu & Buoyancy \\
\hline $\mathrm{Cu}$ & Copper \\
\hline c & Contact line \\
\hline cap & Capillary \\
\hline cyl & Cylinder \\
\hline ext & Extended \\
\hline 1 & Liquid \\
\hline MC & Microchannel \\
\hline Sn & Tin \\
\hline $\mathrm{s}$ & Specimen \\
\hline sat & Saturated \\
\hline st & Surface tension \\
\hline $\mathrm{T}$ & Thermocouple \\
\hline $\mathrm{T} 1, \ldots, \mathrm{T} 8$ & Thermocouple number \\
\hline $\mathrm{v}$ & Vapor \\
\hline W & Wall \\
\hline
\end{tabular}

\section{References}

1. Liang, G.; Mudawar, I. Review of pool boiling enhancement by surface modification. Int. J. Heat Mass Transf. 2019, 128, 892-933. [CrossRef]

2. Webb, R.L. Principles of Enhanced Heat Transfer; Wiley: Hoboken, NJ, USA, 1994.

3. Hożejowska, S.; Kaniowski, R.M.; Poniewski, M.E. Experimental investigations and numerical modeling of 2D temperature fields in flow boiling in minichannels. Exp. Therm. Fluid Sci. 2016, 78, 18-29. [CrossRef] 
4. Piasecka, M.; Strak, K. Influence of the surface enhancement on the flow boiling heat transfer in a minichannel. Heat Transf. Eng. 2019, 40, 1162-1175. [CrossRef]

5. Strak, K.; Piasecka, M. The applicability of heat transfer correlations to flows in minichannels and new correlation for subcooled flow boiling. Int. J. Heat Mass Transf. 2020, 158, 119933. [CrossRef]

6. Piasecka, M.; Strak, K.; Maciejewska, B. Heat transfer characteristics during flow along horizontal and vertical minichannels. Int. J. Multiph. Flow 2021, 137, 103559. [CrossRef]

7. Gil, B.; Rogala, Z.; Dorosz, P. Pool boiling heat transfer coeffcient of low-pressure glow plasma treatedwater at atmospheric and reduced pressure. Energies 2020, 13, 69. [CrossRef]

8. Gil, B.; Fijałkowska, B. Experimental study of nucleate boiling of flammable, environmentally friendly refrigerants. Energies 2020, 13, 160. [CrossRef]

9. Hożejowska, S.; Kaniowski, R.; Pastuszko, R. Application of the Trefftz method for pool boiling heat transfer on open microchannel surfaces. Heat Transf. Eng. 2021, 1-13. [CrossRef]

10. Bedla-Pawlusek, M.; Pastuszko, R.; Kaniowski, R. Comparison of pool boiling heat transfer coefficients for surfaces with open microchannels of variable and constant depths. J. Mach. Constr. Maint. 2019, 112, 59-67.

11. Orman, Ł.J. Boiling heat transfer on meshed surfaces of different aperture. AIP Conf. Proc. 2014, 1608, 169-172. [CrossRef]

12. Orman, Ł.J.; Radek, N.; Pietraszek, J.; Szczepaniak, M. Analysis of enhanced pool boiling heat transfer on laser-Textured surfaces. Energies 2020, 13, 2700. [CrossRef]

13. Cooke, D.; Kandlikar, S.G. Pool boiling heat transfer and bubble dynamics over plain and enhanced microchannels. J. Heat Transf. 2011, 133. [CrossRef]

14. Cooke, D.; Kandlikar, S.G. Effect of open microchannel geometry on pool boiling enhancement. Int. J. Heat Mass Transf. 2012, 55, 1004-1013. [CrossRef]

15. Jaikumar, A.; Kandlikar, S.G. Ultra-high pool boiling performance and effect of channel width with selectively coated open microchannels. Int. J. Heat Mass Transf. 2016, 95, 795-805. [CrossRef]

16. Patil, C.M.; Kandlikar, S.G. Pool boiling enhancement through microporous coatings selectively electrodeposited on fin tops of open microchannels. Int. J. Heat Mass Transf. 2014, 79, 816-828. [CrossRef]

17. Jaikumar, A.; Kandlikar, S.G. Enhanced pool boiling heat transfer mechanisms for selectively sintered open microchannels. Int. J. Heat Mass Transf. 2015, 88, 652-661. [CrossRef]

18. Gheitaghy, A.M.; Samimi, A.; Saffari, H. Surface structuring with inclined minichannels for pool boiling improvement. Appl. Therm. Eng. 2017, 126, 892-902. [CrossRef]

19. Kaniowski, R.; Pastuszko, R.; Nowakowski, Ł. Effect of geometrical parameters of open microchannel surfaces on pool boiling heat transfer. EPJ Web Conf. 2017, 143, 02049. [CrossRef]

20. Rahman, M.M.; McCarthy, M. Effect of length scales on the boiling enhancement of structured copper surfaces. J. Heat Transf. 2017, 139. [CrossRef]

21. Kwak, H.J.; Kim, J.H.; Myung, B.-S.; Kim, M.H.; Kim, D.E. Behavior of pool boiling heat transfer and critical heat flux on high aspect-ratio microchannels. Int. J. Therm. Sci. 2018, 125, 111-120. [CrossRef]

22. Walunj, A.; Sathyabhama, A. Comparative study of pool boiling heat transfer from various microchannel geometries. Appl. Therm. Eng. 2018, 128, 672-683. [CrossRef]

23. Gouda, R.K.; Pathak, M.; Khan, M.K. Pool boiling heat transfer enhancement with segmented finned microchannels structured surface. Int. J. Heat Mass Transf. 2018, 127, 39-50. [CrossRef]

24. Zhang, K.; Bai, L.; Lin, G.; Jin, H.; Wen, D. Experimental study on pool boiling in a porous artery structure. Appl. Therm. Eng. 2019, 149, 377-384. [CrossRef]

25. Li, C.; Peterson, G.P. Parametric study of pool boiling on horizontal highly conductive microporous coated surfaces. J. Heat Transf. 2007, 129, 1465-1475. [CrossRef]

26. Ramaswamy, C.; Joshi, Y.; Nakayama, W.; Johnson, W.B. Semi-analytical model for boiling from enhanced structures. Int. J. Heat Mass Transf. 2003, 46, 4257-4269. [CrossRef]

27. Zhao, Z.; Ma, X.; Li, S.; Yang, S.; Huang, L. Visualization-based nucleate pool boiling heat transfer enhancement on different sizes of square micropillar array surfaces. Exp. Therm. Fluid Sci. 2020, 119, 110212. [CrossRef]

28. Zhou, J.; Zhang, Y.; Wei, J. A modified bubble dynamics model for predicting bubble departure diameter on micro-pin-finned surfaces under microgravity. Appl. Therm. Eng. 2018, 132, 450-462. [CrossRef]

29. Kaniowski, R.; Pastuszko, R. Pool boiling visualization on open microchannel surfaces. EPJ Web Conf. 2017, 143, 02050. [CrossRef]

30. Pastuszko, R.; Kaniowski, R.; Wójcik, T.M. Comparison of pool boiling performance for plain micro-fins and micro-fins with a porous layer. Appl. Therm. Eng. 2020, 166, 114658. [CrossRef]

31. Pastuszko, R. Pool boiling heat transfer on micro-fins with wire mesh-Experiments and heat flux prediction. Int. J. Therm. Sci. 2018, 125, 197-209. [CrossRef]

32. Sajjad, U.; Sadeghianjahromi, A.; Ali, H.M.; Wang, C.-C. Enhanced pool boiling of dielectric and highly wetting liquids-A review on enhancement mechanisms. Int. Commun. Heat Mass Transf. 2020, 119. [CrossRef]

33. Zuber, N. Nucleate boiling. The region of isolated bubbles and the similarity with natural convection. Int. J. Heat Mass Transf. 1963, 6, 53-78. [CrossRef]

34. Jakob, M. Heat Transfer; John Wiley \& Sons: Hoboken, NJ, USA, 1949. 
35. Wang, X.; Wu, Z.; Wei, J.; Sundén, B. Correlations for prediction of the bubble departure radius on smooth flat surface during nucleate pool boiling. Int. J. Heat Mass Transf. 2019, 132, 699-714. [CrossRef]

36. Beer, H. Das dynamische blasenwachstum beim sieden von flüssigkeiten an heizflächen. Forsch. Ing. Wes. 1971, 37, 85-90. [CrossRef] 